\title{
Composição florística e estrutura do componente arbóreo de um trecho de Mata Atlântica na Estação Ecológica Estadual do Paraíso, Cachoeiras de Macacu, Rio de Janeiro, Brasil'
}

\author{
Bruno Coutinho Kurtz ${ }^{2}$ \\ Dorothy Sue Dunn de Araújo ${ }^{3}$
}

\begin{abstract}
RESUMO
O trabalho apresenta os resultados do levantamento fitossociológico do componente arbóreo (DAP $\geq 5 \mathrm{~cm}$ ) de um trecho de Mata Atlântica de encosta, na Estação Ecológica Estadual do Paraíso, Cachoeiras de Macacu, RJ. O clima da área é do tipo A'Ar, com temperatura média de $23,0^{\circ} \mathrm{C}$ e precipitação de $2.558,4 \mathrm{~mm}$ anuais. O solo predominante é da classe Cambissolo. $\mathrm{O}$ levantamento fitossociológico foi realizado pelo método de quadrantes. Nos 150 pontos, foram amostrados 592 indivíduos vivos, distribuídos por 42 famílias, 83 gêneros e 138 espécies, e 8 mortos ainda em pé. As 5 espécies mais importantes são: Neoraputia magnifica var. magnifica, Euterpe edulis, Gallesia integrifolia, Chrysophyllum flexuosum e Calycorectes sellowianus. Myrtaceae apresenta o maior número de indivíduos (18,6\% do total) e de espécies, com 27 (19,6\%) das 138 levantadas. As 5 famílias de maior VI são: Sapotaceae, Myrtaceae, Rutaceae, Meliaceae e Palmae. O índice de diversidade de Shannon (H') é de 4,20 e a equabilidade (J), de 0,85. A mata apresenta dois estratos arbóreos, praticamente contínuos (1,8-18 m; 20-30 m), além de árvores emergentes (até $45 \mathrm{~m}$ ). As distribuições de diâmetro (altura do estipe para Euterpe edulis) das principais espécies amostradas indicam regeneração abundante e estrutura populacional estável. Sugere-se que a mata encontra-se, possivelmente, em clímax ou em estágio sucessional muito próximo.

Palavras-chave: fitossociologia, Mata Atlântica, Rio de Janeiro.
\end{abstract}

\begin{abstract}
A phytosociological survey of the tree component $(\mathrm{DBH} \geq 5 \mathrm{~cm})$ was carried out in an area of Atlantic Forest, in the Paraíso State Ecological Station, Cachoeiras de Macacu, RJ. The local climate is of type $\mathrm{A}^{\prime} \mathrm{Ar}$, with annual mean temperature and precipitation of $23,0^{\circ} \mathrm{C}$ and $2.558,4 \mathrm{~mm}$, respectively. Cambisoils predominate in the area. The point-centered quarter method was used for the phytosociological survey. In 150 points, 592 live trees were sampled, belonging to 42 families, 83 genera and 138 species; there were 8 dead trees. The 5 most important species are: Neoraputia magnifica var. magnifica, Euterpe edulis, Gallesia integrifolia, Chrysophyllum flexuosum and Calycorectes sellowianus. Myrtaceae has the greatest number of individuals (18,6\% of the total) and species, with $27(19,6 \%)$ from a total of 138. Families with the 5 highest IVs are: Sapotaceae, Myrtaceae, Rutaceae, Meliaceae and Palmae. The Shannon diversity index (H') is 4,20 and equability (J), 0,85. The forest has two almost continuous tree strata $(1,8-18 \mathrm{~m} ; 20-30 \mathrm{~m})$, plus the emergent trees (to $45 \mathrm{~m}$ ). Diameter (stem height of Euterpe edulis) distributions of the main species indicate abundant regeneration and stable population structure. This forest is probably at climax or at least approaching the final stage of succession.

Keywords: phytosociology, Atlantic Forest, Rio de Janeiro State, Brazil.

\footnotetext{
${ }^{1}$ Parte da Dissertação de Mestrado apresentada ao Curso de Pós-Graduação em Ciências Biológicas (Botânica), do Museu Nacional da Universidade Federal do Rio de Janeiro.

${ }^{2}$ Pesquisador Titular do Instituto de Pesquisas Jardim Botânico do Rio de Janeiro, Programa Zona Costeira. Rua Pacheco Leão 915, Rio de Janeiro, RJ, CEP 22460-030; tel/fax: (021) 2947526; e-mail: bkurtz@jbrj.gov.br ${ }^{3}$ Professora Assistente do PPGE, Instituto de Biologia, UFRJ. Caixa Postal 68020, Ilha do Fundão, Rio de Janeiro, RJ. CEP 21941-590. Email: dorothy@openlink.com.br
} 


\section{INTRODUÇÃO}

Apesar do seu recente surgimento e expansão na Terra, quando se considera a escala geológica de tempo, o Homem vem destruindo, em ritmo crescente, os ambientes que estão evoluindo há bilhões de anos.

Este processo de agressão, principalmente quando se considera a grande velocidade de destruição e tranformação dos ecossistemas naturais, tem como uma das mais graves consequências a drástica diminuição da biodiversidade. Segundo Soulé (1990), o planeta está a beira de uma extinção antrópica em massa, que exterminará muito da sua diversidade biológica mesmo antes que esta possa ser catalogada.

Sabe-se que o mundo biológico é muito mais rico do que se imaginava há poucas décadas atrás. Pesquisas recentes realizadas nos trópicos (Erwin, 1988, apud Soulé, 1990) aumentaram as estimativas do número de espécies na Terra de alguns milhões para dezenas de milhões, na maior parte artrópodos tropicais. Apesar de não se conhecer o verdadeiro número de espécies, Wilson (1988), com base na fauna e flora descritas e muita discussão com entomologistas e outros especialistas, estima este número entre 5 e 30 milhões. Não obstante, somente cerca de 1,4 milhão de espécies de todos os tipos de organismos já foram descritas e classificadas (Soulé, 1990; Wilson, 1988).

As florestas tropicais, embora cobrindo apenas aproximadamente $7 \%$ da superfície emersa da Terra, contêm mais da metade das espécies de sua biota total. Apesar disto, estas florestas estão sendo destruídas tão rapidamente que desaparecerão em sua maior parte no próximo século, levando centenas de milhares de espécies à extinção (Wilson, 1988). De acordo com Myers (1988), aproximadamente $2 \%$ deste bioma são desmatados ou significativamente degradados por ano, sendo algumas regiões mais duramente afetadas que outras.

O Brasil é considerado o país de flora mais rica do mundo (Giulietti \& Forero, 1990) e também, segundo a IUCN (1988), o que contém a maior extensão de florestas tropicais, com uma área estimada em cerca de 3,6 milhões de $\mathrm{km}^{2}$, em sua grande maioria situadas na Amazônia.

Contrariamente às da bacia Amazônica, que apresentam ainda grandes extensões em bom estado de conservação, as florestas que ocorriam ao longo do litoral brasileiro foram duramente impactadas a partir do processo de colonização.

Fazendo parte deste grande e diversificado corpo florestal e ocupando principalmente as planícies e vertentes voltadas para o mar das serranias costeiras, a Mata Atlântica sensu stricto estendia-se outrora do cabo de São Roque (RN) à região de Osório (RS), ocupando uma área de aproximadamente 1 milhão de $\mathrm{km}^{2}$ (Joly et al., 1991). Atualmente, extremamente fragmentada, está reduzida a manchas disjuntas, concentradas nas regiões Sudeste e Sul, principalmente em locais de topografia acidentada, inadequada às atividades agrícolas, e nas unidades de conservação. Estes remanescentes são o testemunho da formação florestal mais antiga do Brasil, estabelecida há cerca de pelo menos 70 milhões de anos (Leitão-Filho, 1987).

Apesar dos levantamentos florísticos terem se intensificado apenas nos últimos anos, os remanescentes de Mata Atlântica têm mostrado uma extraordinária diversidade florística e um alto índice de endemismos (Mori et al., 1981; Joly et al., 1991; Peixoto, 1991/ 92; Gentry et al., 1997).

Há de se ressaltar ainda que algumas das espécies exclusivas da Mata Atlântica estão limitadas a determinadas localidades, constituindo os endemismos restritos. As serranias do Rio de Janeiro, a região do norte do Espírito Santo/sul da Bahia e o litoral de Pernambuco foram indicados como centros de endemismo da Mata Atlântica (Mori, 1989; Peixoto, 1991/92). Recentemente, as serranias do Rio de Janeiro foram consideradas como um dos 14 centros de diversidade e endemismo de plantas do Brasil (Guedes-Bruni \& Lima, 
1997).

Pelos fatos citados acima, a Mata Atlântica é reconhecida internacionalmente como uma das prioridades em termos de conservação de florestas tropicais (IUCN, 1988; Mori, 1989), sendo tal importância exemplificada quando se considera a alocação de recursos humanos e financeiros, por parte de instituições nacionais e estrangeiras, para o desenvolvimento de pesquisas, recuperação de trechos degradados e tombamento de remanescentes (Comissão de Estudos para o Tombamento do Sistema Serra do Mar/Mata Atlântica no Estado do Rio de Janeiro, 1991).

Apesar dos estudos fitossociológicos no Brasil terem se iniciado no estado do Rio de Janeiro (Davis, 1945; Veloso, 1945), a Mata Atlântica fluminense ainda é muito pouco conhecida sob este enfoque e só muito recentemente os resultados de alguns estudos estão sendo disponibilizados (Guedes, 1988; Oliveira et al., 1995; Rodrigues, 1996; GuedesBruni et al., 1997; Pessoa et al., 1997; Sampaio, 1997; Moreno et al., 1998).

Desta forma, objetivou-se estudar a composição florística e a estrutura fitossociológica do componente arbóreo de um trecho de Mata Atlântica de encosta na Estação Ecológica Estadual do Paraíso, Cachoeiras de Macacu, RJ, contribuindo assim para um maior conhecimento acerca dos recursos florísticos da Mata Atlântica, em especial no estado do Rio de Janeiro, e gerando dados básicos que poderão ser usados na recuperação de trechos degradados deste ecossistema e no desenvolvimento da educação ambiental.

\section{ÁREA DE ESTUDO}

A Estação Ecológica Estadual do Paraíso (22 $27^{\circ}-22^{\circ} 31^{\prime} \mathrm{S}$; 42 $\left.2^{\circ} 50^{\prime}-42^{\circ} 56^{\prime} \mathrm{W}\right)$, criada pelo Decreto no 9.803 de 12 de março de 1987, localiza-se nos municípios de Guapimirim e Cachoeiras de Macacu, Rio de Janeiro, estando a sua administração a cargo da Fundação Estadual de Engenharia do Meio Ambiente, FEEMA. Com área aproximada de 4.920 ha, situa-se na vertente atlântica da serra do Mar, em sua porção denominada serra dos Orgãos, e faz parte do centro de diversidade e endemismo de plantas das serranias do Rio de Janeiro (Guedes-Bruni \& Lima, 1997). As altitudes variam entre $60 \mathrm{~m}$, cuja curva de nível define o limite sul da Estação, e 1.350 m, no alto da serra do Subaio, predominando o relevo fortemente ondulado (Figura 1).

O subsolo é constituído por rochas intrusivas e metamórficas, Pré-Cambrianas, que afloram na maior parte da área, cujos detritos acumulados dão origem a formações superficiais pouco extensas. Estas rochas estão contidas em duas unidades: a Rio Negro, que predomina na Estação, e a Santo Aleixo, que ocorre em menor escala no sul desta. Abundantes diques de gabro e microgabro, de direção semelhante a das principais estruturas falhadas da região, cortam as unidades citadas. Tais diques podem ser correlacionados com os derrames mesozóicos do Brasil meridional. Depósitos de talus e elúvio-coluviais ocorrem, em menor escala, na área. São depósitos detríticos resultantes da desintegração da rocha matriz, que permanecem in situ e podem ser observados nas margens dos vales dos rios (Sérgio V. Granzotto, com. pess.).

A EEEP abriga nascentes e cursos d'água formadores dos rios Paraíso, Anil e Caboclo, que fluem das vertentes íngrimes da serra, em vales encaixados. Constituem mananciais de suma importância e de interesse para o abastecimento humano, a exemplo do rio Paraíso, cujas águas são represadas e distribuídas pela Companhia Estadual de Águas e Esgotos, CEDAE, que mantém na área reservatório e adutora (Martins et al., 1989).

Esta unidade de conservação está sob a influência direta das chuvas de relevo provocadas pela presença do paredão abrupto e dos altos cumes da serra dos Orgãos, que interceptam os ventos úmidos vindos do litoral. Tal fato condiciona uma precipitação anual elevada, entre cerca de 2.000 e $3.000 \mathrm{~mm}$. Em função da grande variação altitudinal, o clima 


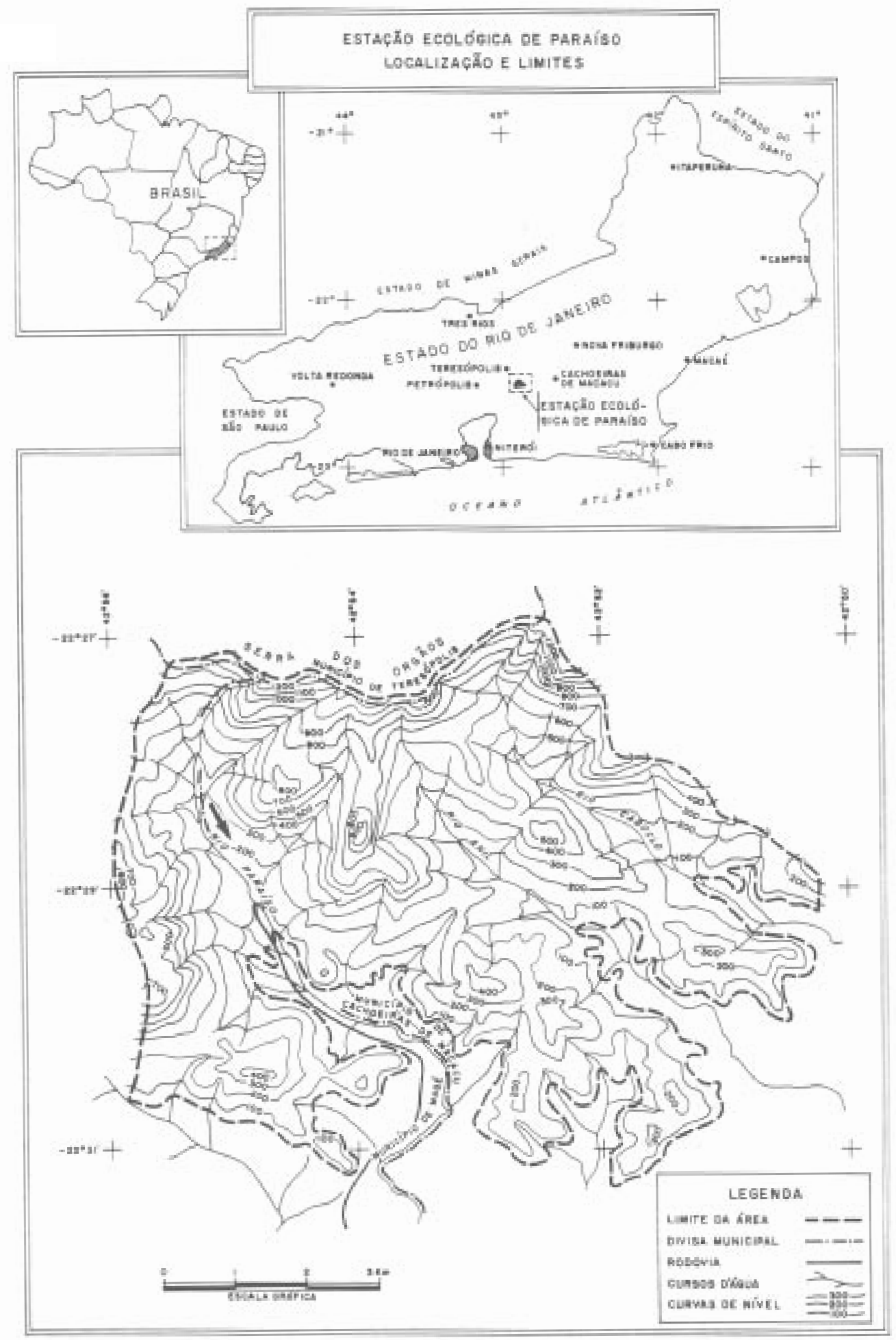

Figura 1 - Localização e limites da Estação Ecológica Estadual do Paraíso. A seta indica o trecho de mata estudado (mapa: Programa Mata Atlântica - Instituto de Pesquisas Jardim Botânico do Rio de Janeiro). 
apresenta-se bastante diversificado. Nas cotas altimétricas inferiores, que correspondem à base da serra, o clima é quente e úmido, sem estação seca, correspondendo ao tipo Af de Koeppen (1948). As encostas e o alto da serra apresentam clima sempre úmido e mesotérmico, dos tipos $\mathrm{Cfa}$ e $\mathrm{Cfb}$, ocorrendo uma gradativa diminuição da temperatura com o aumento da altitude (Bernardes, 1952).

De acordo com o mapa da cobertura vegetal, elaborado pelo Laboratório de Geoprocessamento do Instituto de Pesquisas Jardim Botânico do Rio de Janeiro, com base em fotografias aéreas (escala aproximada de 1:20.000) tomadas em 1973, a EEEP apresentava-se recoberta, em quase sua totalidade, pelas formações submontana e montana da Floresta Ombrófila Densa (Veloso et al., 1991). Além destas, alguns trechos apresentavam matas secundárias ou ocupação agropecuária (pastagens e culturas de subsistência). É bastante provável que muitas das áreas denominadas como Floresta Ombrófila Densa neste levantamento já tivessem sofrido graus variados de interferência humana, principalmente aquelas de acesso mais fácil, bem como que este quadro, de 25 anos, tenha mudado nos dias atuais. Martins et al. (1989) informam, no que diz respeito a vegetação da Estação: “... os adensamentos florestais têm dominância fisionômica na paisagem, recobrindo as encostas e cumeadas, onde ostentam aparente opulência e primitividade. Na verdade são em grande parte formações secundárias em avançado estágio de desenvolvimento, em mistura com contingentes naturais da outrora magnífica mata atlântica, prováveis remanescentes ainda preservados nos trechos mais alcantilados e inacessíveis do relevo. Tais formações vegetais, variáveis em função dos níveis altitudinais, ..." (Figura 2).

A área escolhida para o presente estudo situa-se no município de Cachoeiras de Macacu, numa altitude em torno de $200 \mathrm{~m}$, tendo como coordenadas aproximadas $22^{\circ} 29^{\prime}$ $\mathrm{S}$ e $42^{\circ} 55^{\prime} \mathrm{W}$ (Figura 1). Objetivou-se com esta escolha conciliar o bom estado de conservação da mata e a facilidade de acesso, o que foi conseguido através do levantamento do histórico de ocupação da área, consultas a fotografias aéreas e a antigos moradores da região e incursões a campo. As informações obtidas indicaram não ter havido, nos últimos 60 anos, desmatamentos ou cortes seletivos mais intensos no trecho escolhido. Apesar disto, pôde-se constatar, durante a execução do estudo, a ocorrência de alguns palmiteiros (Euterpe edulis) cortados.

De acordo com Veloso et al. (1991), o trecho estudado apresenta-se recoberto pela formação submontana da Floresta Ombrófila Densa. Situada numa encosta irregular, voltada para o quadrante Sul, a floresta apresenta um dossel não contínuo, entre 20 e $30 \mathrm{~m}$, acima do qual sobressaem alguns indivíduos emergentes que podem atingir mais de $40 \mathrm{~m}$ de altura. Abaixo deste dossel, situa-se um estrato arbóreo contínuo, representado pela grande maioria das árvores. Os estratos arbustivo e herbáceo apresentam-se mais ou menos desenvolvidos, dependendo da situação, condicionando trechos nos quais a locomoção se torna difícil e outros nos quais esta é feita com facilidade. As lianas estão bem representadas, sendo que alguns indivíduos podem apresentar diâmetro superior a $10 \mathrm{~cm}$, enquanto as epífitas, apesar de bem representadas, só exibem maior expressão sobre as árvores de grande porte ou nas proximidades dos cursos d'água e nos trechos mais úmidos da mata.

\section{MATERIAL E MÉTODOS \\ 1. Clima}

Para a caracterização do clima, foram utilizados os dados de temperatura, do período de 1979 a 1988, da Estação Climatológica Escola União (223' S e 42 $56^{\prime}$ 'W, 10 m), da Superintendência Estadual de Rios e Lagoas, SERLA, e da Estação Meteorológica Teresópolis ( $22^{\circ} 27^{\prime} \mathrm{S}$ e $42^{\circ} 56^{\prime} \mathrm{W}, 874 \mathrm{~m}$ ), do Instituto Nacional de Meteorologia, INMET. Estas Estações distam, respectivamente, cerca 


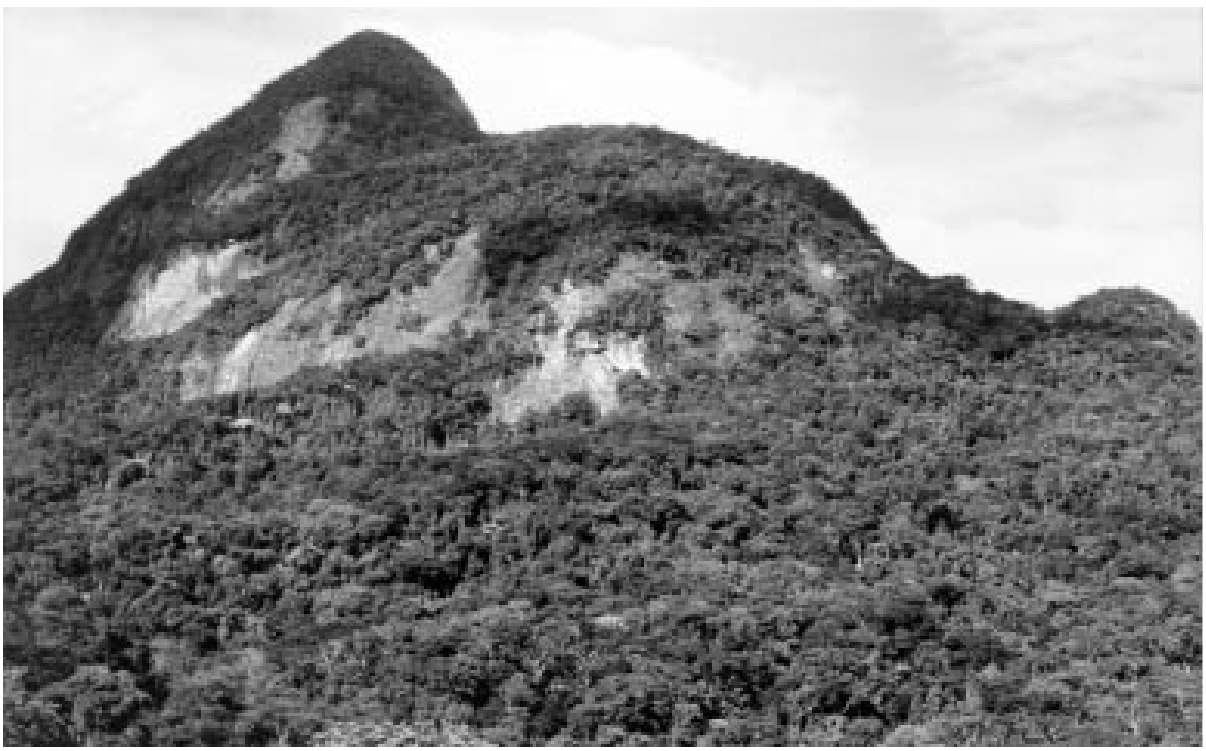

Figura 2 - Aspecto da Mata Atlântica na Estação Ecológica Estadual do Paraíso (foto: M. Peron/ Programa Mata Atlântica - Instituto de Pesquisas Jardim Botânico do Rio de Janeiro).

de 12 e $3,5 \mathrm{~km}$, em linha reta, do trecho de mata estudado. Realizou-se o ajuste dos dados para a altitude de $200 \mathrm{~m}$ (altitude aproximada deste trecho), considerando-se um gradiente de resfriamento da atmosfera de $0,65^{\circ} \mathrm{C}$ para cada 100 m (Blair \& Fite, 1964).

Os dados de chuva, referentes ao mesmo período, foram obtidos da Estação Pluviométrica Represa do Paraíso (22³0' S e 42 $55^{\circ}$ ' W, 60 m), do Departamento Nacional de Águas e Energia Elétrica, DNAEE, que dista aproximadamente $2 \mathrm{~km}$, em linha reta, da área estudada.

O diagrama climático foi construído de acordo com Walter (1971), enquanto o balanço hídrico seguiu Thornthwaite \& Mather (1955, apud Tarifa, 1970), considerando-se uma capacidade de armazenamento de água no solo de $125 \mathrm{~mm}$. Para a determinação do clima, foram utilizadas as classificações de Thornthwaite (1948) e Koeppen (1948).

\section{Solo}

Para a caracterização do solo, foram retiradas 8 amostras, correspondentes aos horizontes A e B incipiente (B câmbico), de 3 locais distintos ao longo da área estudada. Utilizou-se para tal trado holandês, sendo removida a camada de serapilheira (horizonte $\mathrm{O}_{\mathrm{o}}$ ) antes de cada amostragem. As análises foram realizadas pelo Centro Nacional de Pesquisa de Solos, da Empresa Brasileira de Pesquisa Agropecuária, EMBRAPA, utilizando-se a metodologia adotada por esta empresa (EMBRAPA, 1979). Foram determinados os seguintes parâmetros:

- pH em água;

- carbono orgânico;

- nitrogênio total;

- bases trocáveis $\left(\mathrm{Ca}^{++}, \mathrm{Mg}^{++}, \mathrm{K}^{+} \mathrm{e}\right.$ $\mathrm{Na}^{+}$;

- soma de bases (Valor $\mathrm{S}: \mathrm{Ca}^{++}+\mathrm{Mg}^{++}$

$+\mathrm{K}^{+}+\mathrm{Na}^{+}$;

- alumínio trocável $\left(\mathrm{Al}^{+++}\right)$;

- acidez titulável $\left(\mathrm{H}^{+}+\mathrm{Al}^{+++}\right)$;

- capacidade de troca catiônica (Valor $\mathrm{T}$ : Valor $\mathrm{S}+\mathrm{Al}^{+++}+\mathrm{H}^{+}$)

- saturação de bases (Valor V: 100.Valor $\mathrm{S} /$ Valor T);

- saturação de alumínio (100.A1 ${ }^{+++}$ $\left(\right.$ Valor $\left.\mathrm{S}+\mathrm{Al}^{+++}\right)$);

- fósforo assimilável; e

- granulometria.

$\mathrm{Na}$ intenção de se testar possíveis relações do $\mathrm{pH}$ do solo com a saturação de bases e o teor de alumínio trocável, utilizou-se 
o coeficiente de correlação de Pearson (Zar, 1996).

\section{.3. Vegetação}

Utilizou-se o método de quadrantes (Curtis, 1950, apud Cottam \& Curtis, 1956), que tem sido empregado em estudos fitossociológicos de florestas brasileiras, especialmente no estado de São Paulo (Martins, 1989). Martins (1993) discute amplamente o método de quadrantes e, dadas as vantagens deste sobre o de parcelas, recomenda o seu uso, sempre que possível, no estudo de florestas.

3.1. Procedimento no campo Adotou-se, como critério de inclusão, um diâmetro do tronco à altura do peito $(1,30 \mathrm{~m}) \geq$ a $5 \mathrm{~cm}$. Optou-se pela colocação sistemática dos pontos de amostragem, os quais estariam espaçados por uma distância fixa, previamente determinada, ao longo de linhas de picada. Estas linhas estariam, da mesma forma, espaçadas por uma mesma distância.

Para ajustar previamente a distância entre os pontos de amostragem à densidade das árvores na mata, procedeu-se à medição das distâncias entre 100 árvores que atendessem o critério de inclusão, sendo o maior valor encontrado entre árvores mais próximas de 4,69 m. Seguindo sugestão de Martins (1993), de que a distância mínima entre os pontos de amostragem deve ser, pelo menos, igual ao dobro da distância máxima entre as árvores mais próximas, foi estabelecido o valor de $10 \mathrm{~m}$. Mesmo assim, foram desprezados 2 pontos que ocorreram em trechos mais abertos da mata e para os quais as árvores já haviam sido consideradas nos pontos anteriores.

Inicialmente, procedeu-se à abertura de uma linha de picada com $140 \mathrm{~m}$ de comprimento, no sentido oeste-leste, acompanhando aproximadamente o aclive da encosta. Nesta linha foram marcados 15 pontos, a partir dos quais foram abertas outras linhas, perpendiculares à primeira e alternadas: do primeiro ponto, a orientação foi tomada para o norte, enquanto que do segundo, para o sul e assim por diante, até o $15^{\circ}$ ponto. Em cada uma destas linhas, com $90 \mathrm{~m}$ de comprimento (nas 2 linhas cujos pontos foram desprezados o comprimento foi de $100 \mathrm{~m}$ ), foram implantados mais 9 pontos.Desta maneira, foram abertos $1.510 \mathrm{~m}$ de picada e implantados 150 pontos de amostragem, numa área de aproximadamente 2,5 ha.

Em cada ponto, os quadrantes foram estabelecidos pela linha de picada e uma perpendicular passando pelo ponto. Em cada quadrante, foi medida a distância do ponto à árvore mais próxima, adotando-se sempre a altura de 1,30 m. No caso de árvores inclinadas, considerou-se para efeito de distância a projeção vertical de sua base. Para cada distância medida, somou-se posteriormente o raio da árvore considerada (distância corrigida). Os indivíduos mortos ainda de pé também foram considerados.

Para cada árvore assim amostrada, mediu-se também o seu diâmetro à altura do peito (DAP), bem como estimou-se a altura máxima de sua copa (também a altura do estipe para os indivíduos de Euterpe edulis). Para as medidas de DAP, utilizou-se trena com leitura direta para diâmetro, enquanto as estimativas das alturas foram feitas por comparação com as varas da tesoura de poda alta. As árvores com sapopemas tiveram o diâmetro medido logo acima destas. Cada árvore foi numerada com uma etiqueta plástica (fita de rotuladora), sendo esta afixada por meio de prego de cobre.

De todas as árvores vivas amostradas (com exceção dos indivíduos de Euterpe edulis e Astrocaryum aculeatissimum), foram retirados ramos para a identificação taxonômica. A coleta deste material botânico foi realizada com o auxílio de tesoura de poda alta. Para as coletas acima de cerca de $16 \mathrm{~m}$, foi necessária a escalada na própria ou em árvore vizinha, utilizando-se esporão, cinturão de segurança e talabarte. O material botânico recém-coletado foi etiquetado e, ainda no campo, acondicionado em folhas de jornal e prensado. No final de cada dia de trabalho, 
este foi seco em estufa, utilizando-se os procedimentos usuais de herborização.

Buscou-se observar para cada árvore características que pudessem auxiliar na sua determinação, como tipo e cor de casca, cheiro, presença de acúleos, ocorrência e cor de látex ou exsudato, etc. Estas observações, bem como todas as medidas anteriormente citadas, foram registradas em planilhas desenvolvidas para o estudo.

Todas as atividades de campo relacionadas com a implantação do método de quadrantes foram realizadas por 3 pessoas, sendo uma delas o auxiliar de campo, indispensável para este tipo de trabalho.

.3.2. Composição florística e parâmetros fitossociológicos - O material botânico coletado foi separado por famílias e posteriormente em morfoespécies. Para a identificação taxonômica, utilizou-se a bibliografia disponível e a comparação com o material depositado no herbário do Instituto de Pesquisas Jardim Botânico do Rio de Janeiro (RB), além de consultas a especialistas. Adotou-se o sistema de classificação de Cronquist (1988), com exceção da família Leguminosae, que seguiu Polhill et al. (1981). Ao menos uma exsicata de cada espécie amostrada, mesmo estéril, foi incluída no acervo deste herbário. Os nomes populares foram obtidos do Sr. Beijamim da Silva, antigo morador e ex-madeireiro da região.

Com o objetivo de se verificar a suficiência da amostragem, foram elaboradas as curvas observada e teórica do número de espécies pelo de pontos de amostragem. Para tal, seguiu-se o procedimento proposto por Martins (1993), sendo que no presente trabalho foram considerados acréscimos de quinze espécies. Desta forma, calculou-se o fator médio de acréscimo do número de pontos de amostragem, para acréscimos de 15 espécies, como sendo igual a 1,23. Para ajustar a curva teórica à observada, foram testados vários valores de $\mathrm{x}_{1}$, na seguinte ordem: $5 ; 6 ; 5,5 ; 5,4$; 5,6; 5,7; 5,8 e 5,9. A menor diferença total entre os valores observados e teóricos de $\mathrm{x}_{i}$ foi obtida com $x_{1}=5,8$. Segundo Martins (1993), este ajuste permite predizer com maior precisão o acréscimo do número de pontos de amostragem para obter-se um determinado acréscimo do número de espécies.

Os dados de distância ponto-planta, DAP, altura, família e espécie das árvores amostradas foram registrados no sistema gerenciador de banco de dados para levantamentos ecológicos ECOLOG ${ }^{1}$. Para o cálculo dos parâmetros fitossociológicos, estes registros foram exportados para o conjunto de programas para análises fitossociológicas FITOPAC ${ }^{2}$. Tais parâmetros foram estimados de acordo com Cavassan et al. (1984) e Martins (1993), sendo que no presente estudo a distância média foi calculada como a média aritmética das distâncias individuais corrigidas. Os parâmetros fitossociológicos estimados foram os seguintes:

DTA - densidade total por área

DA - densidade por área proporcional

DR - densidade relativa

FA - frequência absoluta

FR - frequência relativa

DoA - dominância por área

DoR - dominância relativa

VI - valor de importância

VC - valor de cobertura

Foram elaborados histogramas do percentual de espécies para as classes de número de indivíduos, frequência absoluta, valor de importância e valor de cobertura, nos quais o limite superior de cada classe foi incluído nesta.

3.3. Diversidade e equabilidade - Para se estimar a diversidade do trecho de mata estudado, utilizou-se o índice de Shannon (H') (Magurran, 1988), de acordo com as fórmulas:

\footnotetext{
${ }^{1}$ Desenvolvido pelo Prof. Mauro J. Cavalcanti, do Departamento de Biologia Geral do Centro de Ciências Biológicas da Universidade Santa Úrsula, USU, RJ.

${ }^{2}$ Desenvolvido pelo Prof. Dr. George J. Shepherd, do Departamento de Morfologia e Sistemática Vegetais do Instituto de Biologia da Universidade Estadual de Campinas, UNICAMP, SP.
} 
a) $\mathrm{H}^{\prime}=-\Sigma \mathrm{p}_{i} \cdot \ln \mathrm{p}_{i}$

b) $\mathrm{p}_{i}=\mathrm{n}_{i} / \mathrm{N}$

onde:

$\mathrm{n}_{i}$ é o número de indivíduos amostrados da espécie $i$; e

$\mathrm{N}$ é o número total de indivíduos amostrados.

A equabilidade (J), foi calculada através da fórmula (Pielou, 1975, apud Sugiyama, 1993):

$$
\mathrm{J}=\mathrm{H}^{\prime} / \ln \mathrm{S}
$$

onde:

H'é o índice de diversidade de Shannon; e

$\mathrm{S}$ é o número total de espécies amostradas.

Os valores de H' e J foram calculados pelo conjunto de programas FITOPAC.

3.4. Estratificação - Para a avaliação da distribuição vertical das copas e caracterização dos estratos da mata estudada, construiu-se o histograma de frequência das classes de altura de todas as árvores vivas amostradas. Para tal, considerou-se um intervalo de classe de $1 \mathrm{~m}$, sendo o limite superior de cada classe incluído nesta.

Com o mesmo objetivo e visando evitar um possível efeito de agrupamento em relação as classes de altura consideradas, procedeuse à construção de um gráfico, no qual todas as árvores vivas foram organizadas, no eixo $\mathrm{x}$, por ordem crescente de altura, representando o eixo y a escala de altura. A curva resultante da união dos pontos correspondentes às alturas destas árvores denominou-se curva diferencial de alturas (Fernando R. Martins, com. pess.). Uma maior concentração de copas num determinado intervalo vertical condicionaria pequena inclinação desta curva no intervalo correspondente, ao passo que um intervalo com poucas copas produziria uma faixa de maior inclinação. Considerando-se um estrato como sendo uma maior concentração de copas num determinado intervalo vertical, estes poderiam ser definidos e quantificados através do comportamento da curva diferencial.

3.5. Distribuição de frequência das classes de diâmetro e altura - Para a avaliação de alguns aspectos da dinâmica do trecho de mata estudado e das principais populações ali presentes, foram elaborados histogramas de frequência das classes de diâmetro de todos os indivíduos vivos amostrados e para as espécies que apresentaram um mínimo de 15 indivíduos. $\mathrm{O}$ intervalo de classe ideal (IC) para cada situação foi calculado conforme as fórmulas (Spiegel, 1970, apud Felfili \& Silva-Júnior, 1988):

a) $\mathrm{IC}=\mathrm{A} / \mathrm{NC}$

b) $\mathrm{NC}=1+3,3 \cdot \log \mathrm{N}$

onde:

A é a amplitude de diâmetros;

NC é o número de classes; e

$\mathrm{N}$ é o número de indivíduos.

O limite inferior de cada classe de diâmetro foi incluído na respectiva classe.

Para a população de Euterpe edulis, dadas as características do crescimento do tronco desta espécie (Silva, 1980), considerouse a distribuição de frequência das classes de altura do estipe e não de diâmetro, adotandose o mesmo procedimento exposto acima.

\section{RESULTADOS E DISCUSSÃO \\ 1. Clima}

Os valores médios mensais e anuais de temperatura média, precipitação e dias com chuva, para o período de 1979 a 1988, são apresentados na Tabela 1. Fevereiro, com temperatura média de $26,6^{\circ} \mathrm{C}$, é o mês mais quente, enquanto junho e julho, com $19,7^{\circ} \mathrm{C}$, são os meses mais frios. A temperatura média 
anual é de $23,0^{\circ} \mathrm{C}$. No que se refere à precipitação, janeiro é o mês mais chuvoso, com 504,2 mm, e julho, com 76,7 mm, o mais seco, sendo o total anual de $2.558,4 \mathrm{~mm}$. Dezembro e janeiro são os meses que apresentam os maiores números de dias com chuva (19,7 e 19,6, respectivamente), ao passo que julho é o que apresenta o menor $(5,4)$. Por ano chove, em média, 143,8 dias.

A comparação da curva de temperatura com a de precipitação é cientificamente relevante, porque a primeira pode ser usada como uma medida da variação anual da evaporação (Walter, 1971). A curva de temperatura indica o lado de débito das relações hídricas enquanto a curva de precipitação mostra o lado de crédito, transmitindo juntas alguma idéia do balanço hídrico ou das condições hídricas.

Ainda de acordo com Walter (1971), foi visto empiricamente que um período seco ocorre para as plantas quando a curva de precipitação corta a de temperatura, na escala $\mathrm{T}: \mathrm{P}=1: 2$ (adotada no diagrama climático). A análise da Figura 3 evidencia a inexistência de qualquer período seco ao longo do ano. Contrariamente, o diagrama indica um extenso período superúmido, do início de setembro ao início de maio (no qual a precipitação mensal excede $100 \mathrm{~mm}$ ), alternando-se com um período úmido nos meses restantes.

Construiu-se o balanço hídrico de Thornthwaite \& Mather (1955, apud Tarifa, 1970), apresentado na Figura 4, considerandose uma capacidade de armazenamento de água no solo de $125 \mathrm{~mm}$. Por este gráfico, evidencia-se que os valores médios de precipitação mensal são sempre superiores aos de evapotranspiração potencial, denotando não existir qualquer deficiência hídrica ao longo do ano, mesmo nos meses de menor quantidade de chuvas. Nesta situação, a evapotranspiração real iguala-se à potencial, com um valor de $1.180 \mathrm{~mm}$. O excedente hídrico anual é de $1.378 \mathrm{~mm}$.

De acordo com a classificação de Thornthwaite (1948), o clima do local estudado é do tipo A'Ar, megatérmico, superúmido, sem déficit de água. Seguindo-se Koeppen (1948), o clima é do tipo Af, tropical, megatérmico, chuvoso, sem período seco.

\section{Solo}

A área de estudo está contida na associação $\mathrm{Ca}_{5}+\mathrm{AR}+\mathrm{RHa}_{1}: \mathrm{Ca}_{5}-$ Cambissolo, $\mathrm{Tb}$, álico ou distrófico, $\mathrm{A}$ proeminente ou moderado, textura argilosa ou média, fase rochosa ou não rochosa, floresta tropical perenifólia, relevo montanhoso ou

Tabela 1 -Médias mensais e anuais de temperatura média, precipitação e dias com chuva, para o período de 1979-1988.

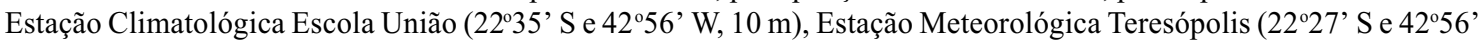
W, 874 m) e Estação Pluviométrica Represa do Paraíso (22³0' S e 4255’ W, 60 m). Fontes: SERLA, INMET e DNAEE.

\begin{tabular}{lccc}
\hline Meses & Temp. média $\left({ }^{\circ} \mathrm{C}\right)^{*}$ & Precipitação $(\mathrm{mm})$ & Dias com chuva \\
\hline Janeiro & 25,8 & 504,2 & 19,6 \\
Fevereiro & 26,6 & 269,8 & 13,7 \\
Março & 25,6 & 248,3 & 12,4 \\
Abril & 23,5 & 172,4 & 12,3 \\
Maio & 22,1 & 91,7 & 7,9 \\
Junho & 19,7 & 89,5 & 6,4 \\
Julho & 19,7 & 76,7 & 5,4 \\
Agosto & 20,3 & 81,1 & 7,7 \\
Setembro & 20,6 & 133,4 & 11,7 \\
Outubro & 22,8 & 181,6 & 13,4 \\
Novembro & 24,4 & 249,3 & 13,6 \\
Dezembro & 25,2 & 460,4 & 19,7 \\
Ano & 23,0 & $2.558,4$ & 143,8 \\
\hline
\end{tabular}

* Valores ajustados para a altitude de $200 \mathrm{~m}$ (altitude aproximada do trecho de mata estudado), considerando-se um gradiente de resfriamento da atmosfera de $0,65^{\circ} \mathrm{C}$ para cada $100 \mathrm{~m}$. 


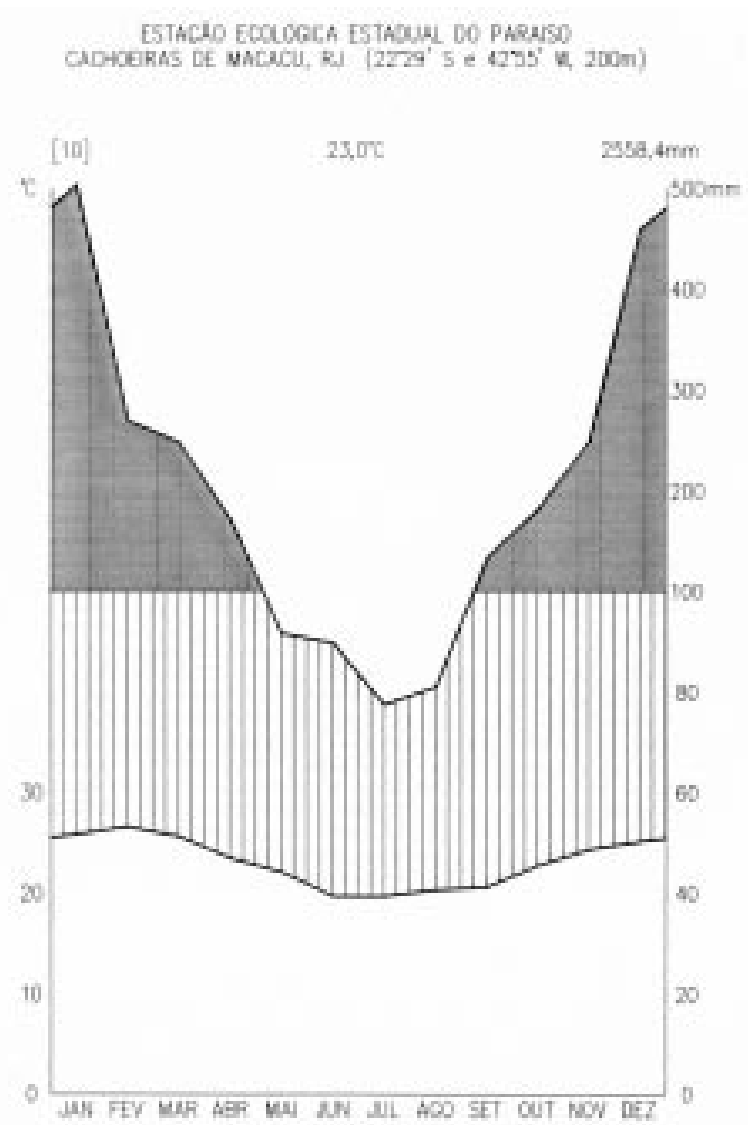

Figura 3 - Diagrama climático da área de estudo, de acordo com Walter (1971), baseado em dados termopluviométricos do período de 1979-1988. Fontes: SERLA, INMET e DNAEE.

escarpado; AR - Afloramentos rochosos; e $\mathrm{RHa}_{1}$ - Solo litólico, húmico, Tb, álico, textura média, fase rochosa, floresta tropical perenifólia, relevo montanhoso (EMBRAPA, inéd.).

Os perfis analisados correspondem ao primeiro membro da citada associação, sendo classificados da seguinte maneira: perfil 1 Cambissolo, $\mathrm{Tb}$, álico, epidistrófico, raso, A moderado, textura média, fase rochosa, floresta tropical perenifólia, relevo montanhoso; perfil 2 - Cambissolo, Tb, álico, pouco profundo, A moderado, textura média, fase rochosa, floresta tropical perenifólia, relevo ondulado; e perfil 3 - Cambissolo, Tb, álico, profundo, A moderado, textura média, fase rochosa, floresta tropical perenifólia, relevo montanhoso. A fase rochosa

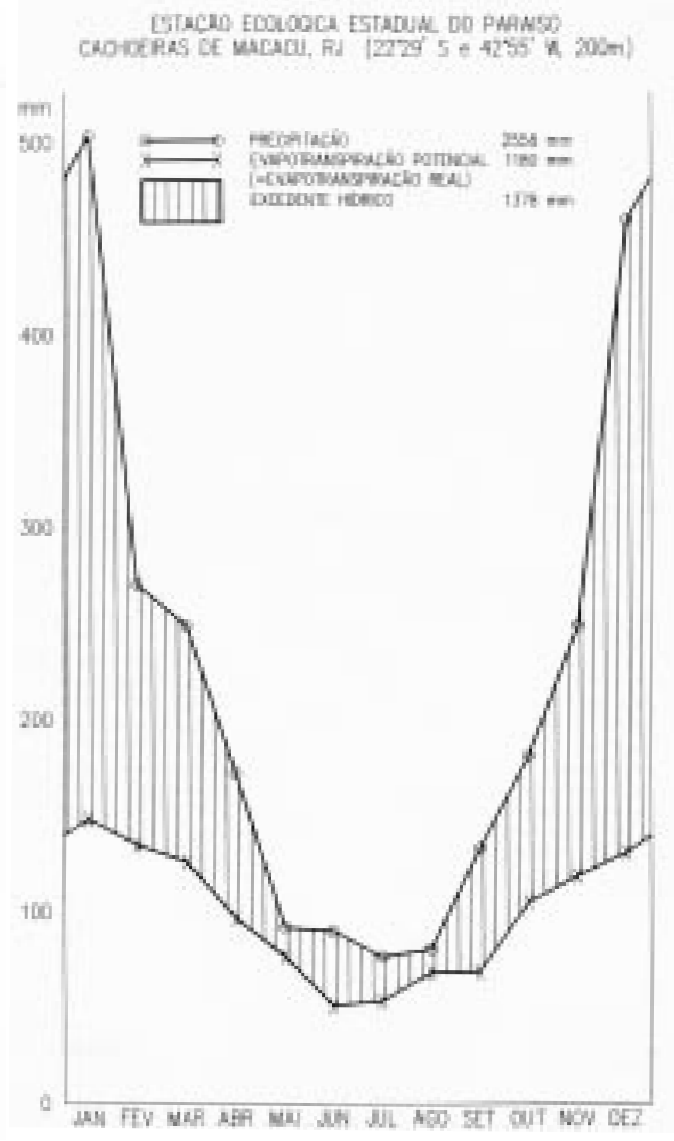

Figura 4 - Balanço hídrico da área de estudo, segundo Thornthwaite \& Mather (1955, apud Tarifa, 1970), baseado em dados termopluviométricos do período de 1979-1988. Capacidade de armazenamento de água no solo de $125 \mathrm{~mm}$. Fontes: SERLA, INMET e DNAEE.

se refere a blocos de tamanhos variados (até alguns metros de diâmetro), de ocorrência generalizada na área.

Os resultados das análises químicas das amostras de solo são apresentados na Tabela 2 , enquanto os resultados da análise granulométrica estão na Tabela 3.

Em relação à acidez, medida pelo $\mathrm{pH}$, observa-se que os perfis se mostram, em geral, fortemente ácidos (EMBRAPA, 1988), a exceção do horizonte superficial (A) do perfil 1 , que se apresenta no limite inferior da classe moderadamente ácida.

A acidificação do solo consiste, geralmente, da remoção de cátions básicos (cálcio, magnésio, potássio e sódio) do complexo de troca catiônica (Valor T), os quais 
Tabela 2 -Resultados das análises químicas do solo de trecho de mata na Estação Ecológica Estadual do Paraíso, Cachoeiras de Macacú, RJ. S - soma de bases; T - capacidade de troca catiônica; e V - saturação de bases.

\begin{tabular}{|c|c|c|c|c|c|c|c|c|c|c|c|c|c|c|c|c|c|}
\hline \multirow[t]{2}{*}{$\mathrm{A} / \mathrm{P}^{*}$} & \multirow[t]{2}{*}{ Horiz. } & Prof. & \multirow[t]{2}{*}{$\mathrm{pH}$} & $\mathrm{C}$ & $\mathrm{N}$ & $\mathrm{C} / \mathrm{N}$ & $\mathrm{Ca}^{++}$ & $\mathrm{Mg}^{++}$ & $\mathrm{K}^{+}$ & $\mathrm{Na}^{+}$ & $\mathrm{S}$ & $\mathrm{Al}^{\prime++}$ & $\mathrm{H}^{+}$ & $\mathrm{T}$ & \multirow{2}{*}{$\begin{array}{l}\mathrm{V} \\
\%\end{array}$} & \multirow{2}{*}{$\begin{array}{c}\text { Sat. } \\
\mathrm{Al}^{\prime+} \\
\%\end{array}$} & \multirow{2}{*}{$\begin{array}{c}\mathrm{P} \\
\mathrm{ppm}\end{array}$} \\
\hline & & $\mathrm{cm}$ & & $\%$ & $\%$ & & \multicolumn{8}{|c|}{ meq $/ 100 \mathrm{~g}$ TFSA } & & & \\
\hline $1-1$ & $\overline{\mathrm{A}}$ & $0-18$ & $\overline{5,4}$ & 1,37 & 0,18 & 8 & 2,5 & 0,5 & 0,53 & 0,04 & 3,6 & 1,6 & 3,9 & 9,1 & 39 & 31 & 10 \\
\hline $2-1$ & $\mathrm{Bi}$ & $18-45$ & 5,3 & 0,70 & 0,10 & 7 & 1,0 & 0,3 & 0,28 & 0,03 & 1,6 & 2,1 & 2,0 & 5,7 & 28 & 57 & 26 \\
\hline $3-2$ & A & $0-25$ & 5,1 & 1,63 & 0,29 & 6 & 1,9 & 0,6 & 0,44 & 0,03 & 3,0 & 3,8 & 3,8 & 10,6 & 28 & 56 & 30 \\
\hline $4-2$ & Bil & $25-60$ & 5,1 & 0,69 & 0,12 & 6 & 0,8 & 0,7 & 0,12 & 0,04 & 1,7 & 3,8 & 2,0 & 7,5 & 23 & 69 & 37 \\
\hline $5-2$ & Bi2 & $60-100$ & 5,1 & 0,50 & 0,10 & 5 & 0,6 & 0,5 & 0,14 & 0,04 & 1,3 & 3,5 & 1,7 & 6,5 & 20 & 73 & 43 \\
\hline $6-3$ & A & $0-20$ & 4,6 & 1,25 & 0,20 & 6 & \multicolumn{2}{|c|}{0,7} & 0,20 & 0,02 & 0,9 & 5,4 & 2,0 & 8,3 & 11 & 86 & 6 \\
\hline $7-3$ & Bil & $20-60$ & 4,6 & 0,79 & 0,14 & 6 & \multicolumn{2}{|c|}{0,5} & 0,15 & 0,03 & 0,7 & 5,2 & 0,8 & 6,7 & 10 & 88 & 4 \\
\hline $8-3$ & $\mathrm{Bi} 2$ & $60-100$ & 4,9 & 0,29 & 0,06 & 5 & \multicolumn{2}{|c|}{0,5} & 0,22 & 0,03 & 0,7 & 5,2 & 0,3 & 6,2 & 11 & 88 & 4 \\
\hline
\end{tabular}

* $\mathrm{A} / \mathrm{P}=$ Amostra/Perfil

Tabela 3 -Resultados da análise granulométrica do solo de trecho de mata na Estação Ecológica Estadual do Paraíso, Cachoeiras de Macacú, RJ.

\begin{tabular}{|c|c|c|c|c|c|c|c|c|c|c|}
\hline \multirow[t]{2}{*}{$\mathrm{A} / \mathrm{P}^{*}$} & \multirow[t]{2}{*}{ Horiz. } & \multirow{2}{*}{$\begin{array}{l}\text { Prof. } \\
\mathrm{cm}\end{array}$} & \multicolumn{3}{|c|}{ Frações da amostra total (\%) } & \multicolumn{4}{|c|}{ Composição granulométrica da terra fina (\%) } & \multirow[t]{2}{*}{ Classificação textural } \\
\hline & & & $\begin{array}{l}\text { Calhaus } \\
>20 \mathrm{~mm}\end{array}$ & $\begin{array}{l}\text { Cascalho } \\
20-2 \mathrm{~mm}\end{array}$ & $\begin{array}{l}\text { Terrafina } \\
<2 \mathrm{~mm}\end{array}$ & $\begin{array}{l}\text { Areiagrossa } \\
2-0,2 \mathrm{~mm}\end{array}$ & $\begin{array}{r}\text { Areia fina } \\
0,2-0,05 \mathrm{~mm}\end{array}$ & $\begin{array}{c}\text { Silte } \\
0,05-0,002 \mathrm{~mm}\end{array}$ & $\begin{array}{c}\text { Argila } \\
<0,002 \mathrm{~mm}\end{array}$ & \\
\hline $1-1$ & $\mathrm{~A}$ & $0-18$ & 0 & 10 & 90 & 55 & 15 & 11 & 19 & Franco arenoso \\
\hline $2-1$ & $\mathrm{Bi}$ & $18-45$ & 0 & 11 & 89 & 55 & 18 & 11 & 16 & Franco arenoso \\
\hline $3-2$ & A & $0-25$ & 0 & 6 & 94 & 42 & 16 & 16 & 26 & Franco argilo-arenoso \\
\hline $4-2$ & Bil & $25-60$ & 0 & 7 & 93 & 44 & 20 & 11 & 25 & Franco argilo-arenoso \\
\hline $5-2$ & $\mathrm{Bi} 2$ & $60-100$ & 0 & 10 & 90 & 50 & 17 & 8 & 25 & Franco argilo-arenoso \\
\hline $6-3$ & A & $0-20$ & 0 & 7 & 93 & 47 & 13 & 13 & 27 & Franco argilo-arenoso \\
\hline $7-3$ & Bi1 & $20-60$ & 0 & 6 & 94 & 42 & 16 & 10 & 32 & Franco argilo-arenoso \\
\hline $8-3$ & $\mathrm{Bi} 2$ & $60-100$ & 0 & 6 & 94 & 44 & 13 & 9 & 34 & Franco argilo-arenoso \\
\hline
\end{tabular}

* A/P = Amostra/Perfil

são substituídos por alumínio trocável e hidrogênio não dissociado (Raij, 1991). Desta forma, é normal se observar uma correlação significativa e positiva entre o $\mathrm{pH}$ do solo e a saturação de bases (Valor V), visto que esta última é a relação entre a soma dos cátions básicos (Valor $\mathrm{S}$ ) e a capacidade de troca catiônica (Valor T). De fato, no caso dos horizontes estudados, esta correlação é observada $(\mathrm{r}=0,913)$, corroborando a afirmação anterior. Observa-se também uma correlação altamente significativa e negativa entre o $\mathrm{pH}$ e o teor de alumínio trocável $(r=-0,936)$, sugerindo que realmente sejam os processos de perda das bases e enriquecimento em alumínio que estejam controlando o $\mathrm{pH}$.

Com relação à fertilidade, compreendida como sendo a quantidade de nutrientes presentes no solo, nota-se que ocorre um decréscimo considerável dos teores de cálcio, magnésio, potássio e nitrogênio com o aumento da profundidade (no caso de cálcio, magnésio e potássio, este decréscimo pode ser melhor visualizado através do comportamento do Valor S). Tal fato de certo modo já era esperado, visto que os processos de ciclagem de nutrientes realizados pelos seres vivos, 
principalmente vegetais, tornam a camada superficial mais rica nestes nutrientes (Duchaufour, 1982).

Contrariamente, observa-se um acréscimo dos teores de fósforo assimilável com o aumento da profundidade nos perfis $1 \mathrm{e}$ 2 , além de serem estes extremamente elevados para os solos brasileiros (Oliveira $e t$ al., 1992).

Deve-se ressaltar que os perfis apresentam teores de alumínio bem elevados, o que, em geral, causa problemas de fitotoxidez. De acordo com Martins (1993), valores de alumínio trocável acima de $0,5 \mathrm{meq} /$ 100 g TFSA são considerados tóxicos. Contudo, é bem conhecida a existência de florestas tropicais nestas condições (Cochrane et al. 1985; Lepsch, 1993).

A quantidade de matéria orgânica presente no solo é medida indiretamente pelo teor de carbono orgânico, visto que se considera, geralmente, que $58 \%$ desta seja composta de carbono (EMBRAPA, 1979). Assim sendo, observa-se que os teores de carbono orgânico diminuem com a profundidade, sendo este um resultado também esperado posto que o maior aporte de matéria orgânica faz-se a partir da superfície, pela serapilheira (Martins, 1993).

Com respeito à relação $\mathrm{C} / \mathrm{N}$, os valores encontrados oscilam entre 5 e 8 , indicando que a matéria orgânica do solo está humificada, ou seja, está estabilizada, passando a sofrer uma lenta mineralização de seus nutrientes (Baruqui, 1983).

Considerando-se as classes primárias de textura em nível mais generalizado (EMBRAPA, 1988), os horizontes dos perfis analisados apresentam textura média, observando-se uma certa uniformidade com a profundidade (Tabela 3 ).

\section{Vegetação}

1. Composição florística e parâmetros fitossociológicos - Foram amostrados, nos 150 pontos, 592 indivíduos vivos e 8 mortos ainda em pé. Os indivíduos vivos distribuem-se por 42 famílias, 83 gêneros e 138 espécies. A Tabela 4 lista estas espécies, bem como os respectivos nomes populares locais.

Tabela 4 - Lista das espécies amostradas na Estação Ecológica Estadual do Paraíso, Cachoeiras de Macacu, RJ, ordenadas por família, e seus respectivos nomes populares locais.

\begin{tabular}{ll}
\hline Famílias/Espécies & Nomes populares \\
\hline ANNONACEAE & \\
Oxandra martiana (Schltdl.) R.E. Fr. & imbiú preto \\
Oxandra nitida R.E. Fr. & imbiú amarelo \\
Unonopsis sp. & imbiú preto \\
APOCYNACEAE & \\
Aspidosperma ramiflorum Müll. Arg. & \\
Geissospermum laevis (Vell.) Miers & pau pereira \\
Malouetia arborea (Vell.) Miers & coerana \\
BIGNONIACEAE & \\
Tabebuia serratifolia (Vahl) Nicholson & ipê \\
Tabebuia stenocalyx Sprague et Stapf & tabibuia \\
BOMBACACEAE & \\
Chorisia speciosa A. St. Hil. & \\
Quararibea turbinata (Sw.) Poir. & paineira \\
Quararibea sp. & \\
BORAGINACEAE & \\
Cordia sellowiana Cham. & \\
\hline
\end{tabular}

Rodriguésia 51(78/115): 69-112. 2000 
Famílias/Espécies

BURSERACEAE

Protium widgrenii Engl.

CARICACEAE

Jacaratia spinosa (Aubl.) A. DC.

CELASTRACEAE

Maytenus communis Reissek

CHRYSOBALANACEAE

Licania kunthiana Hook. f.

CLUSIACEAE

Garcinia brasiliensis Mart.

Garcinia gardneriana (Planch. et Triana) Zappi

COMBRETACEAE

Terminalia januariensis DC.

CONNARACEAE

Connarus detersus Planch.

ELAEOCARPACEAE

Sloanea guianensis (Aubl.) Benth.

ERYTHROXYLACEAE

Erythroxylum cuspidifolium Mart.

EUPHORBIACEAE

Drypetes sessiliflora Allemão

Hyeronima alchorneoides Allemão

Pausandra megalophylla Müll. Arg.

Senefeldera verticillata (Vell.) Croizat

FLACOURTIACEAE

Casearia pauciflora Cambess.

Flacourtiaceae sp.

HIPPOCRATEACEAE

Salacia amygdalina Peyr.

Salacia grandifolia (Mart.) G. Don

ICACINACEAE

Citronella megaphylla (Miers) R.A. Howard

LAURACEAE

Beilschmiedia emarginata (Meisn.) Kosterm.

Beilschmiedia stricta Kosterm.

Cryptocarya micrantha Meisn.

Cryptocarya moschata Nees et Mart. ex Nees

Cryptocarya saligna $\mathrm{Mez}$

Cryptocarya sp.

Ocotea daphnifolia (Meisn.) Mez

Ocotea diospyrifolia (Meisn.) Mez

Ocotea dispersa (Nees) Mez

Ocotea divaricata (Nees) Mez

Ocotea sp.1

Ocotea $\mathrm{sp} .2$

Phyllostemonodaphne geminiflora (Meisn.) Kosterm.

Lauraceae sp.

\section{Nomes populares}

sindiba

mamão jacatiá

sindiba

bacupariu

bacupariu

mirindiba

ouriceiro

iricurana

sucanga

canela tatu

sindiba branca

canela

canela

canela

canela

canela

canela

canela

canela

canela ruiva 
Composição florística e estrutura do componente arbóreo de um trecho de Mata Atlântica na Estação Ecológica Estadual do Paraíso, Cachoeiras de Macacu, Rio de Janeiro, Brasil

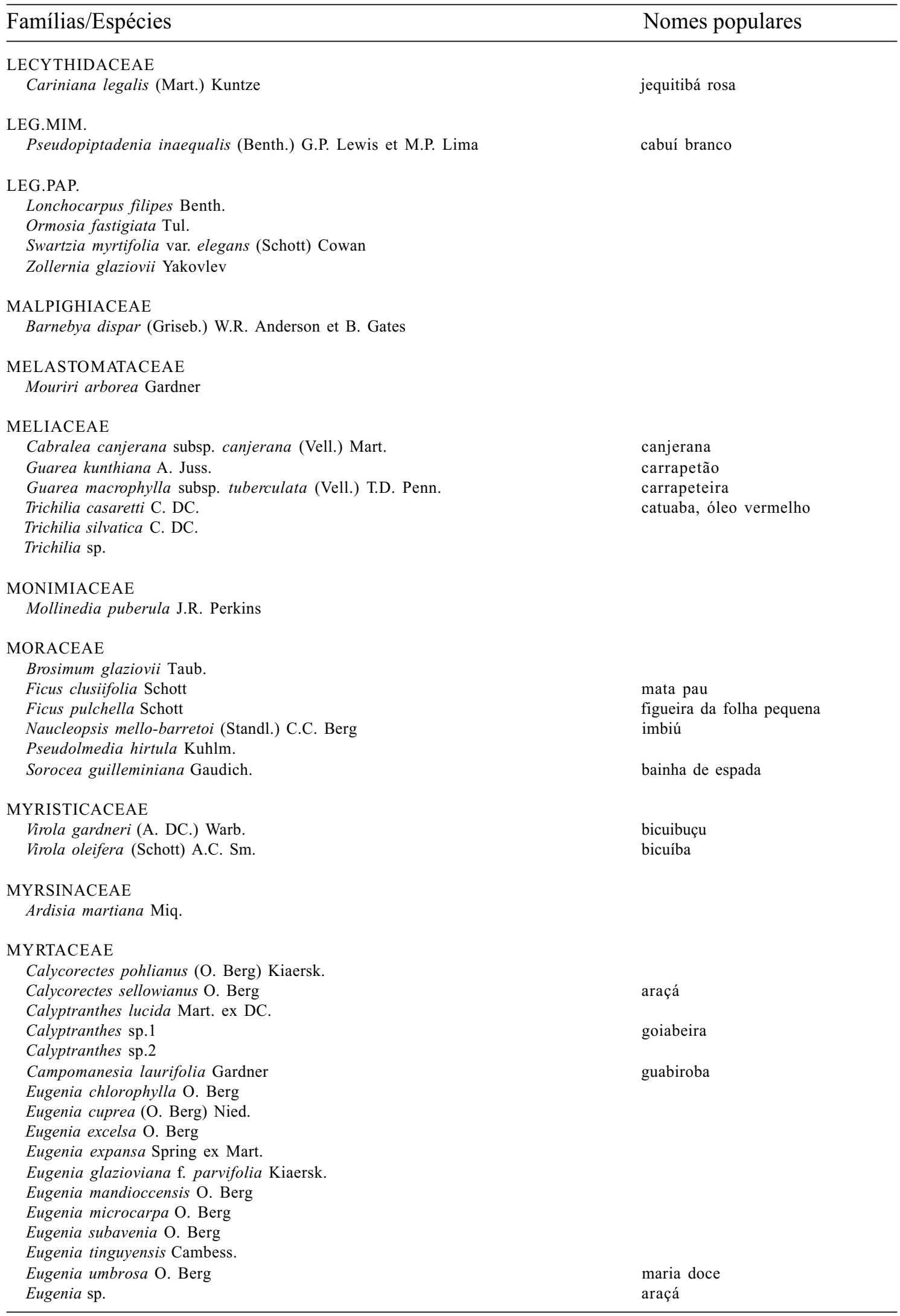




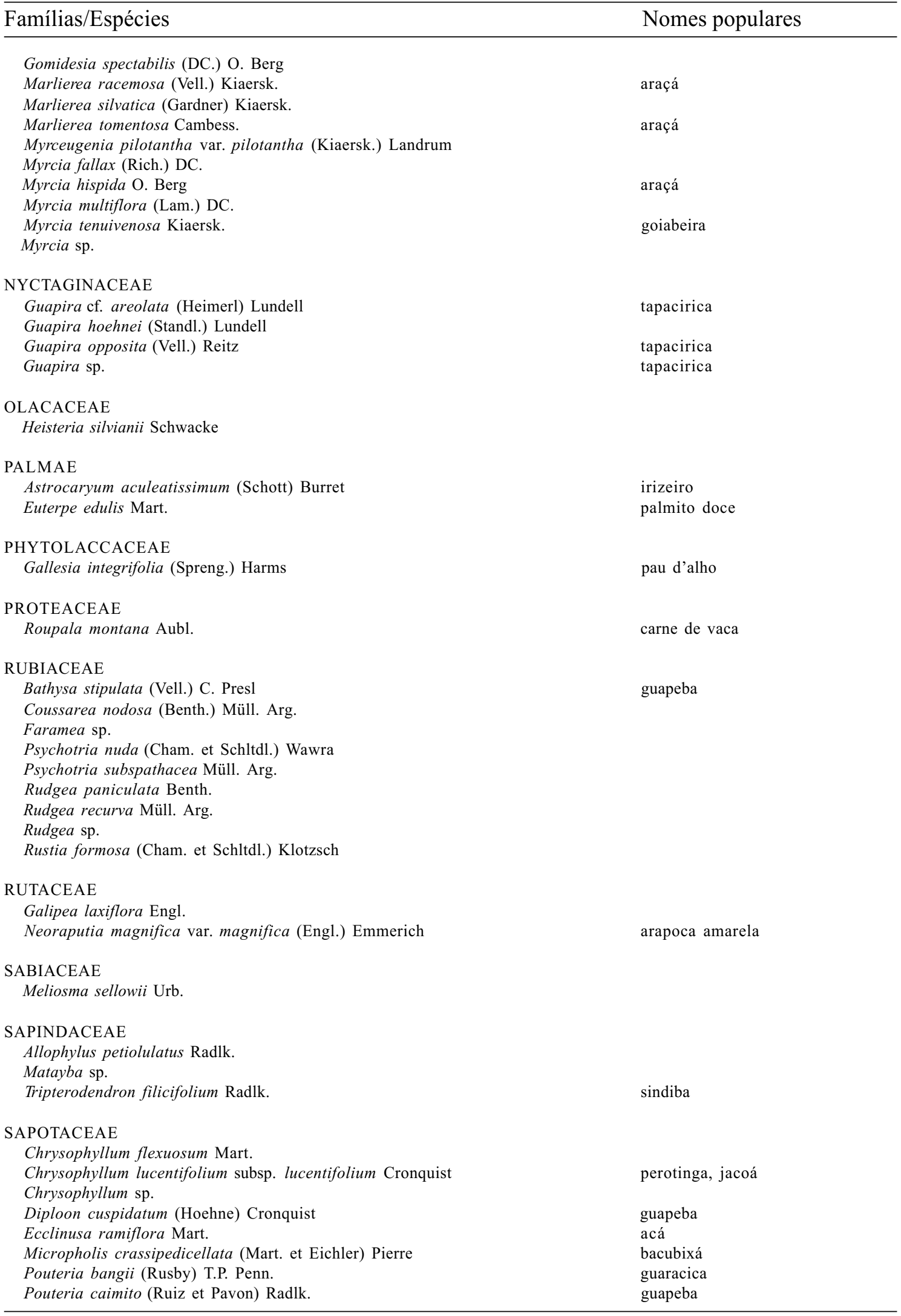


Composição florística e estrutura do componente arbóreo de um trecho de Mata Atlântica na

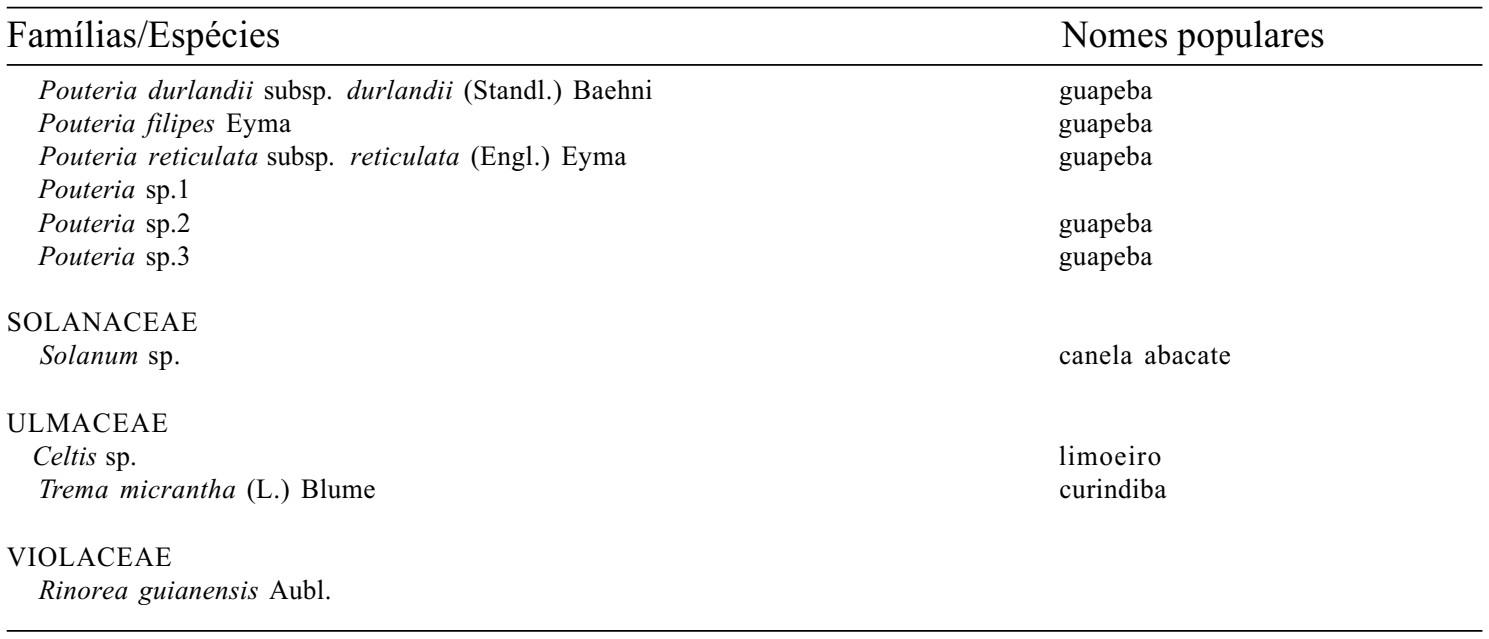

$\mathrm{Na}$ Figura 5 são apresentas as curvas observada e teórica do número de espécies pelo de pontos de amostragem. O comportamento da curva observada evidencia que os 150 pontos utilizados neste trabalho são ainda insuficientes para uma representação mais ampla da mata estudada, incluindo aquelas populações com baixa densidade.

De acordo com a curva teórica, para o aparecimento de 15 espécies inéditas (a partir da $135^{a}$ amostrada), seria necessária a implantação de mais 37 pontos, isto é, para um acréscimo de $11,1 \%$ do número de espécies, seria necessário um acréscimo de $27,2 \%$ do número de pontos. Para acréscimos de mais 30 e 45 espécies, que correspondem a 22,2 e $33,3 \%$ do número de espécies, seriam necessários, respectivamente, mais 83 e 140 pontos de amostragem (60,7 e 101,9\%).

Desta forma, teoricamente, mesmo aumentando-se o número de pontos para 277 (quase o dobro do número implantado), aquela ampla representação ainda não seria completamente alcançada. Tal situação está relacionada à grande riqueza florística da área, ao alto percentual de espécies com populações de baixa densidade (ver adiante) e ao fato da amostragem ter sido realizada ao longo de aproximadamente 2,5 ha de uma encosta irregular, abrangendo distintas situações topográficas e sucessionais.

A etapa mais difícil e trabalhosa deste estudo foi a identificação dos indivíduos coletados, aspecto igualmente apontado por

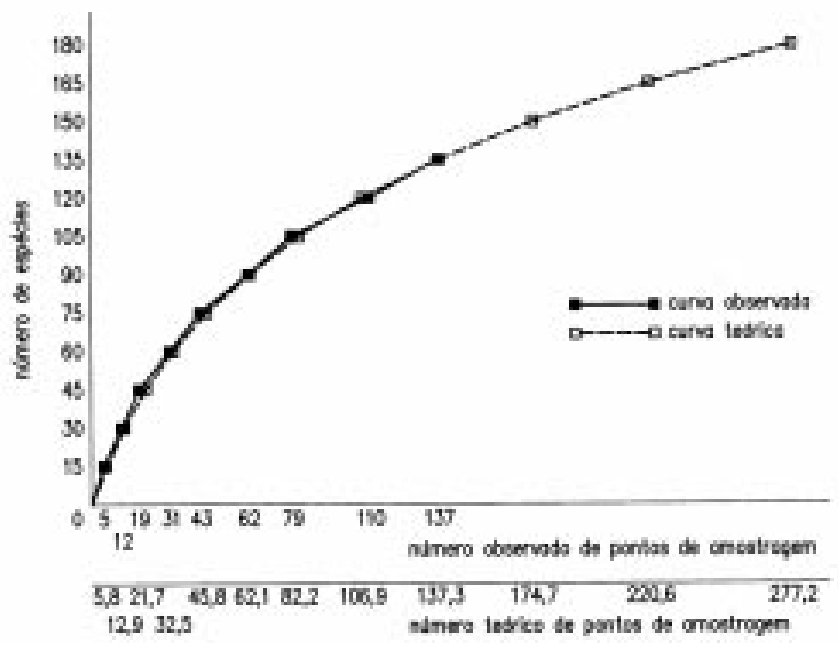

Figura 5 - Curvas observada e teórica do número de espécies em relação ao número de pontos de amostragem. 
Martins (1993). A carência de bibliografia especializada (floras e revisões taxonômicas), o ainda escasso conhecimento dos recursos florísticos da Mata Atlântica, a pouca representatividade de alguns grupos taxonômicos em herbário e o grande volume de material estéril, inerente aos estudos fitossociológicos, condicionaram tal dificuldade. Por estes motivos, justifica-se o fato de uma parte deste material estar determinada apenas a nível de gênero e mesmo de família.

Como mencionado anteriormente, foram amostrados 592 indivíduos vivos e 8 mortos ainda de pé. A distância média é de 2,70 m, conduzindo a uma área média ocupada por árvore de 7,30 $\mathrm{m}^{2}$. A densidade total por área é de 1.369,9 indivíduos/ha e a área basal, de $57,28 \mathrm{~m}^{2} /$ ha.

A Tabela 5 apresenta as espécies, em ordem decrescente de VI, e seus respectivos parâmetros fitossociológicos. Também estão assinalados o número de indivíduos, as alturas mínima, máxima e média e os diâmetros mínimo, máximo e médio para cada espécie. As árvores mortas estão reunidas num grupo único.

A Figura 6 mostra o percentual de espécies para as classes de número de indivíduos, observando-se que a grande maioria das espécies $(83,3 \%)$ está representada por até 5 indivíduos. Sessenta e duas espécies $(44,9 \%)$ ocorrem na amostragem com apenas um indivíduo e $85(61,6 \%)$ apresentam até 2 indivíduos.

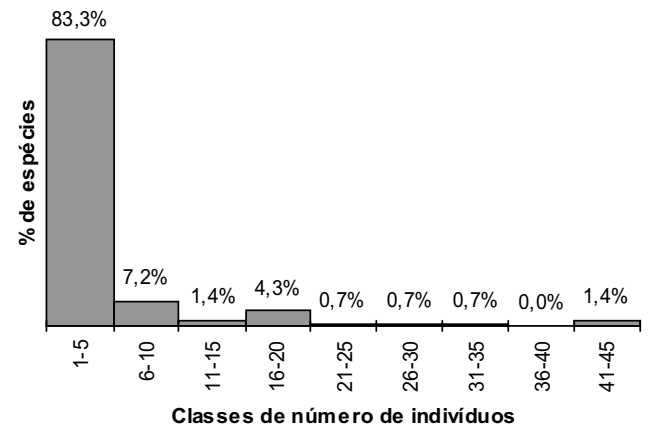

Figura 6 - Percentual de espécies nas classes de número de indivíduos.
Considerando como raras aquelas espécies que ocorreram nas amostragens com apenas um indivíduo, Martins (1993) comparou algumas florestas brasileiras quanto a este parâmetro. Nas florestas amazônicas, a percentagem variou de 25,1 a $56,0 \%$; nas florestas atlânticas, de 9,2 a 39,5\%; e nas florestas do interior paulista, de 25,5 a 29,9\%.

Os estudos realizados na Mata Atlântica dos estados da Paraíba (Mayo \& Fevereiro, 1982), Bahia (Moriet al., 1983), Rio de Janeiro (Davis, 1945, apud Martins, 1993; Guedes, 1988; Oliveira et al., 1995; Guedes-Bruni et al., 1997; Pessoa et al., 1997), São Paulo (Silva \& Leitão-Filho, 1982; Mantovani et al., 1990; Leitão-Filho, 1993; Mantovani, 1993; Melo \& Mantovani, 1994) e Santa Catarina (Veloso \& Klein, 1957, apud Martins, 1993) indicaram que o percentual de espécies raras variou de 9,2, em Santa Catarina, a 64,3\%, em São Paulo. Já no estado do Rio de Janeiro, este percentual variou de 9,5 a $45,2 \%$.

A análise dos estudos acima citados indica que o percentual de espécies raras amostradas no presente estudo $(44,9 \%)$ situase entre os maiores valores encontrados para a Mata Atlântica. Entretanto, a comparação destes percentuais não deve ser feita de maneira muito rígida, uma vez que o método de estudo e o critério de inclusão utilizados, além do esforço de amostragem empreendido, influenciam tais percentuais. Como exemplo, cita-se Rudgea sp., arvoreta que, embora frequente em alguns trechos do interior da mata, foi amostrada por apenas um indivíduo em função do critério de inclusão utilizado (DAP ${ }^{3}$ a $5 \mathrm{~cm}$ ).

De acordo com Mantovani (1993), para as espécies amostradas por um único indivíduo, poderia se pensar no fato de serem raras, com recrutamento também raro, ou de se encontrarem em extinção na área. Não por estar em extinção no trecho de mata estudado, mas por ser espécie pioneira, cita-se Trema micrantha, provável testemunho de antiga clareira, também amostrada por apenas um indivíduo. 
馬

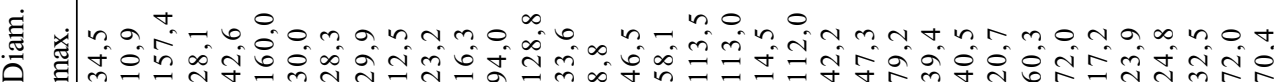

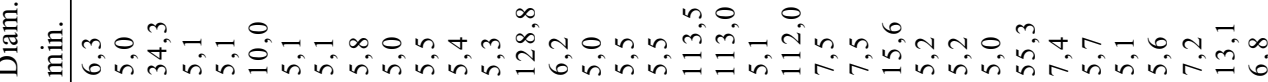

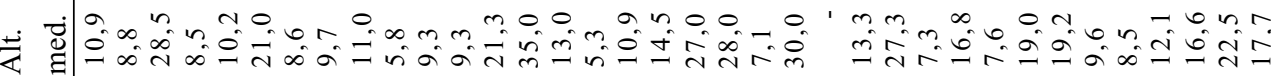
0000000000000000000010000000000000

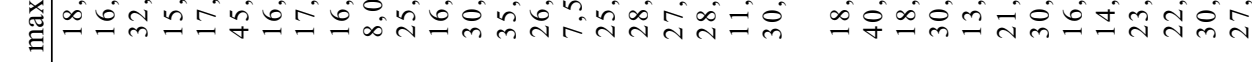

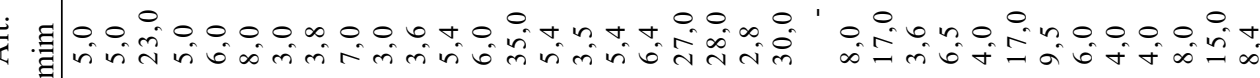
(

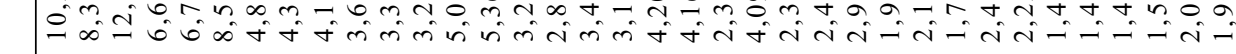

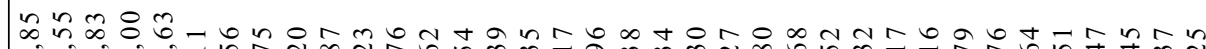

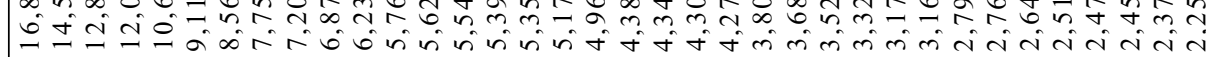

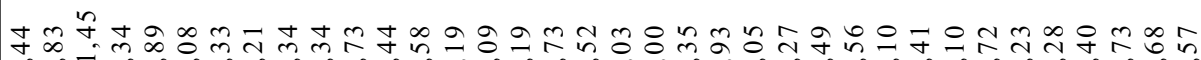

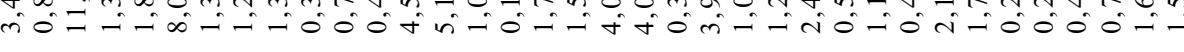

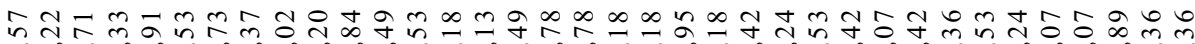

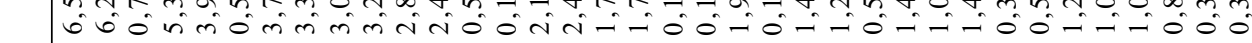

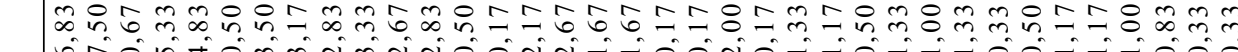

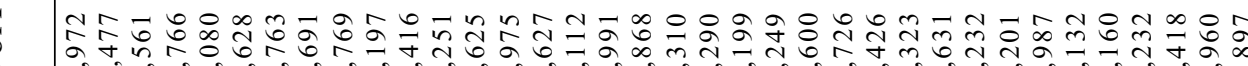

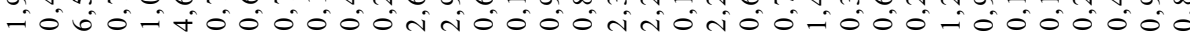

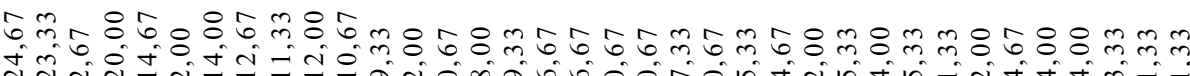
ర ố.

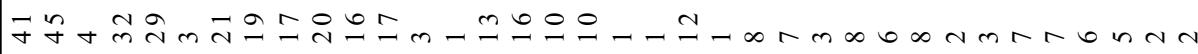

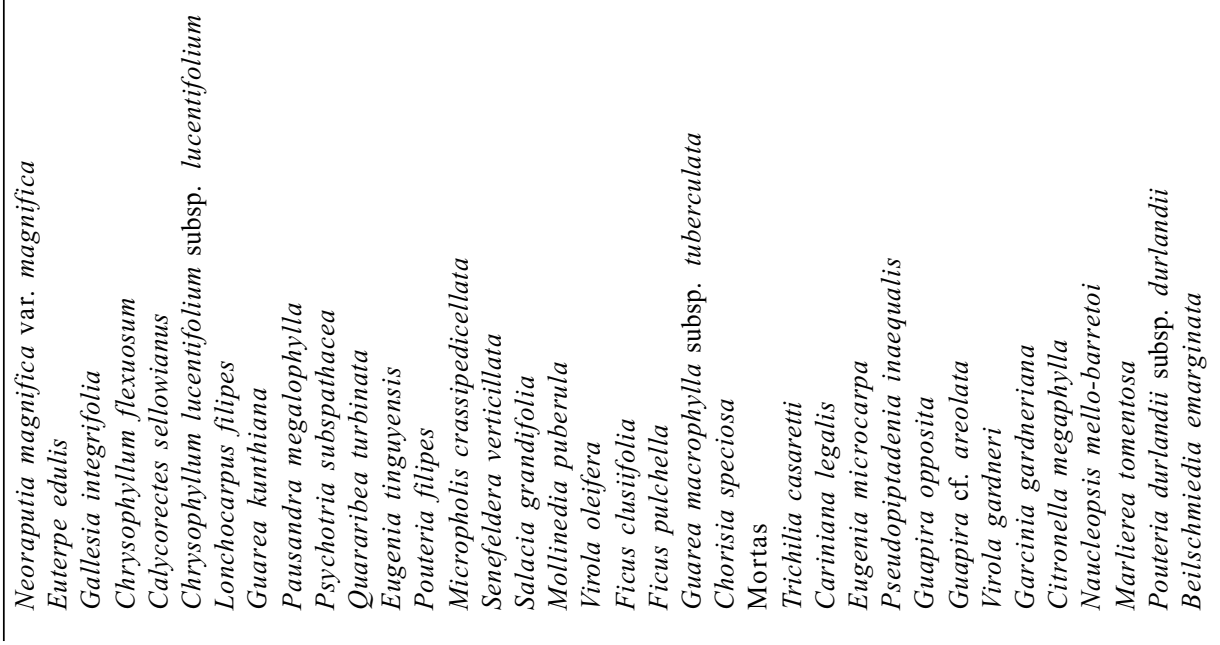




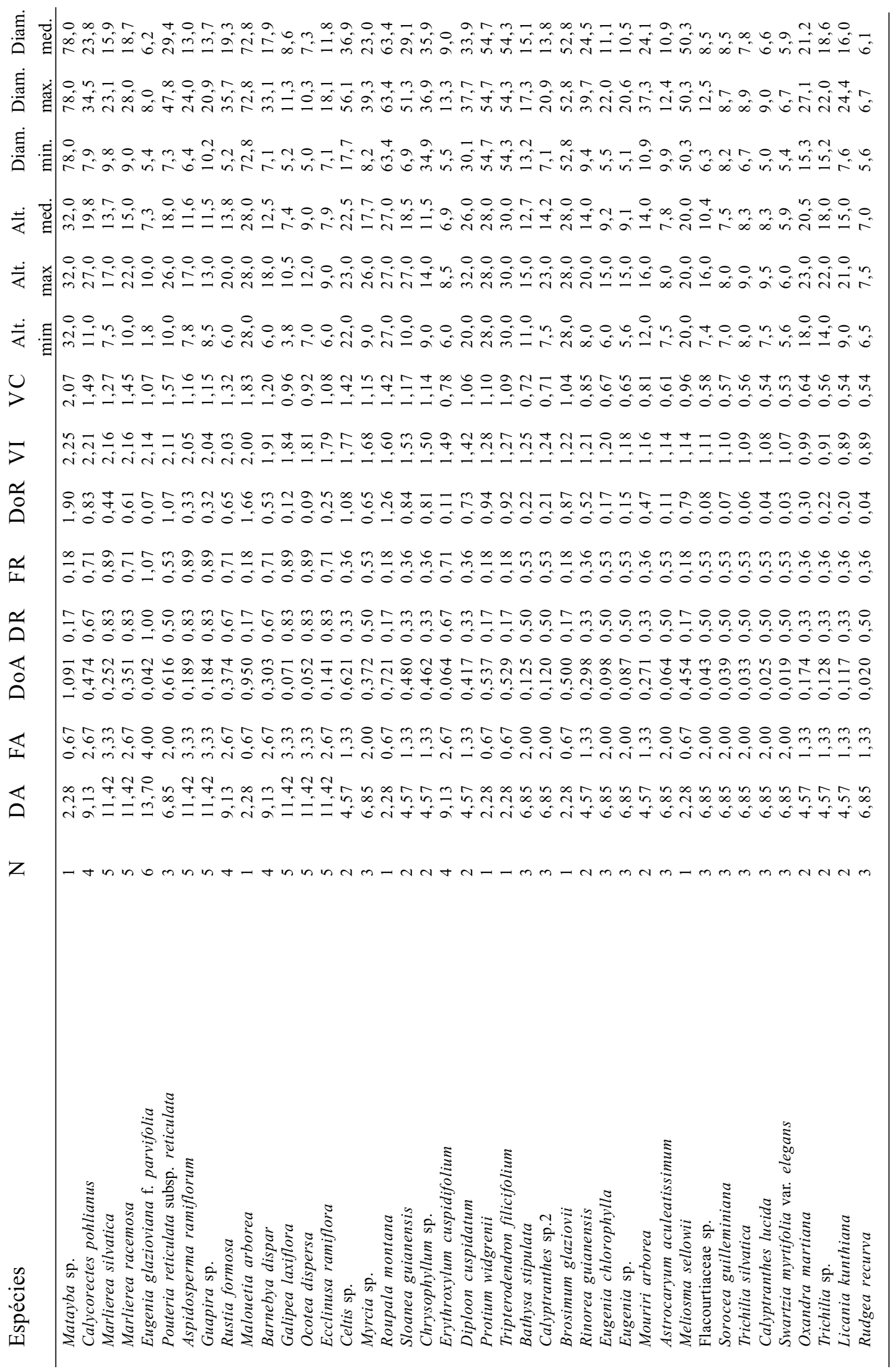




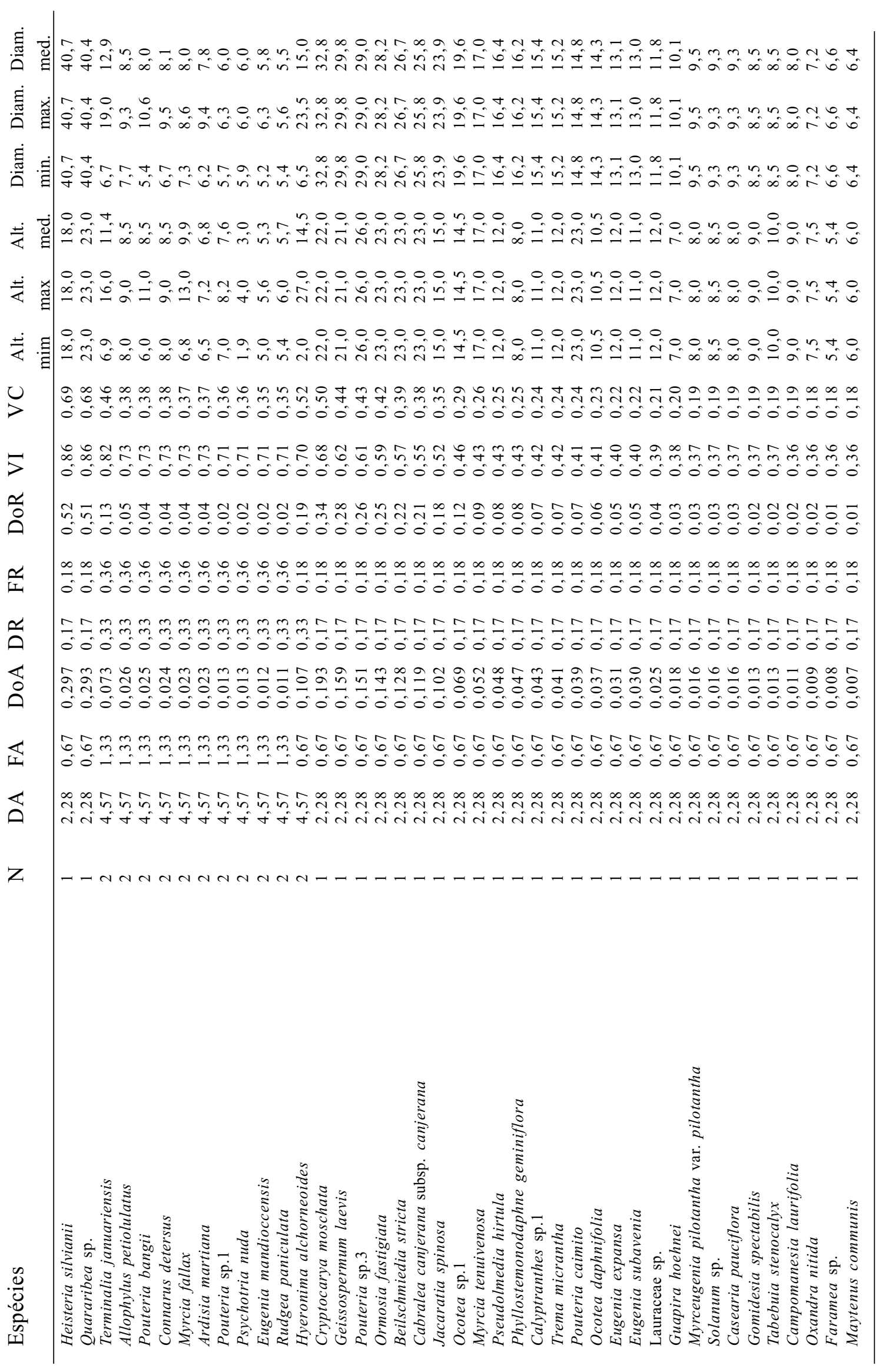




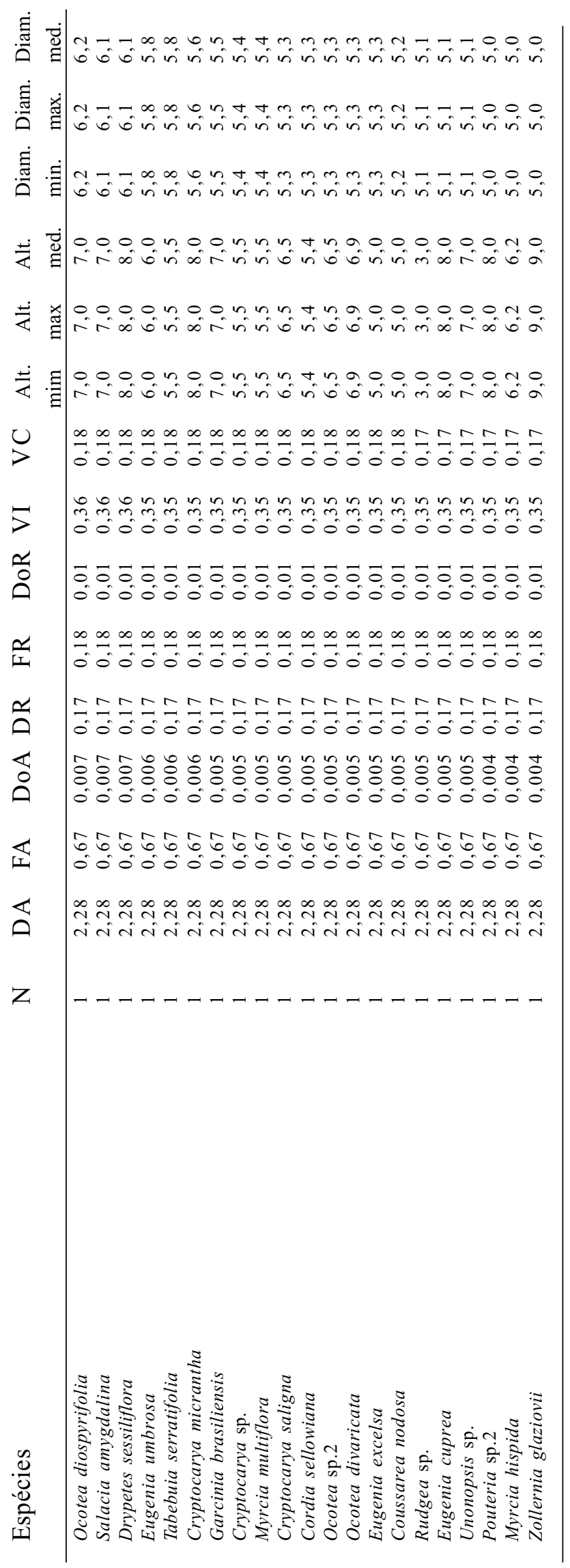


Ainda segundo Mantovani (1993), “o conceito de espécies raras deve considerar diferentes escalas de análise, já que uma população pode ser rara num local e abundante em outro, considerando-se escalas maiores, como a paisagem, na qual a população pode distribuir-se com poucos indivíduos em vários locais".

Por outro lado, Euterpe edulis (45 indivíduos), Neoraputia magnifica var. magnifica (41), Chrysophyllum flexuosum (32), Calycorectes sellowianus (29), Lonchocarpus filipes (21), Psychotria subspathacea (20), Guarea kunthiana (19), Pausandra megalophylla (17), Eugenia tinguyensis (17), Quararibea turbinata (16) e Salacia grandifolia (16), que representam $8,0 \%$ das espécies amostradas, perfazem $46,1 \%$ do total de indivíduos vivos amostrados.

É apresentado na Figura 7 o percentual de espécies para as classes de frequência absoluta. Nota-se que a quase totalidade das espécies $(98,6 \%$, incluindo o grupo de mortas) apresenta valores de até $20 \%$. Apenas Neoraputia magnifica var. magnifica e Euterpe edulis apresentam valores superiores, de 24,7 e 23,3\%, respectivamente, destacandose também Chrysophyllum flexuosum, com $20,0 \%$.

Observa-se na Tabela 5 que algumas espécies, apesar de representadas por apenas um ou poucos indivíduos, se destacam em relação aos valores de dominância, em função dos elevados diâmetros que estes podem atingir. Desta forma, Gallesia integrifolia (DoA de $6,56 \mathrm{~m}^{2} / \mathrm{ha}$ ), Chrysophyllum lucentifolium subsp. lucentifolium $(4,63)$, Micropholis crassipedicellata (2,98), Pouteria filipes (2,63), Ficus clusiifolia (2,31), F. pulchella (2,29) e Chorisia speciosa $(2,25)$, que representam $5,1 \%$ das espécies amostradas, perfazem $41,7 \%$ da área basal das árvores vivas.

A Figura 8 mostra o percentual de espécies para as classes geometricamente crescentes de VI, sendo as árvores mortas consideradas como um grupo único. Nota-se que, de um modo geral, é pequena a importância das espécies amostradas, sendo que $54,7 \%$ destas apresentam VI de até $1,2 \mathrm{e}$ $92,1 \%$, de até 6,0 . Considerando-se a ordenação da Tabela 5 , são necessárias 44 espécies $(31,7 \%)$ para que se atinja $75,2 \%$ da soma total dos valores de importância.

Poucas espécies apresentam algum destaque em relação ao VI. Na Figura 8, 3 espécies compõem a maior classe de importância: Neoraputia magnifica var. magnifica (VI de 16,9), Euterpe edulis $(14,6)$ e Gallesia integrifolia $(12,8)$. Compondo a classe de 6,0 a 12,4 , estão 8 espécies: Chrysophyllum flexuosum (12,0), Calycorectes sellowianus $(10,6)$, Chrysophyllum lucentifolium subsp. lucentifolium $(9,1)$, Lonchocarpus filipes $(8,6)$, Guarea kunthiana $(7,8)$, Pausandra megalophylla (12) Psychotria subspathacea $(6,9)$ e Quararibea turbinata $(6,2)$.

Destas espécies, N. magnifica var. magnifica, E. edulis, C. flexuosum, $C$. sellowianus, L. filipes, G. kunthiana, $P$. megalophylla, $P$. subspathacea e $Q$. turbinata destacam-se basicamente em função do grande número de indivíduos, que condiciona elevados valores de DR e FR. Por outro lado, G. integrifolia e C. lucentifolium subsp. lucentifolium destacam-se pelo grande porte de parte de seus poucos indivíduos, conduzindo a elevados valores de DoR.

Desta maneira, das 11 espécies mais importantes, 9 apresentam, como estratégia de ocupação do ambiente, muitos indivíduos de porte relativamente reduzido, enquanto 2 apresentam poucos indivíduos que podem alcançar grandes dimensões.

E. edulis, segunda colocada em relação ao VI, tem sido apontada como uma das espécies mais importantes em outros trechos de Mata Atlântica, nos estados do Rio de Janeiro e São Paulo, tanto em matas em bom estado de conservação como em matas perturbadas ou secundárias (Silva \& LeitãoFilho, 1982; Guedes, 1988; Mantovani et al., 


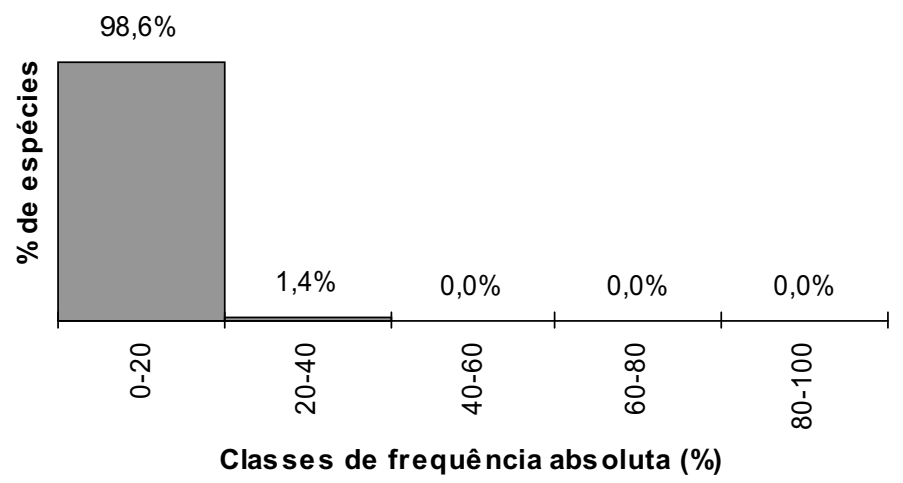

Figura 7 - Percentual de espécies nas classes de frequência absoluta.

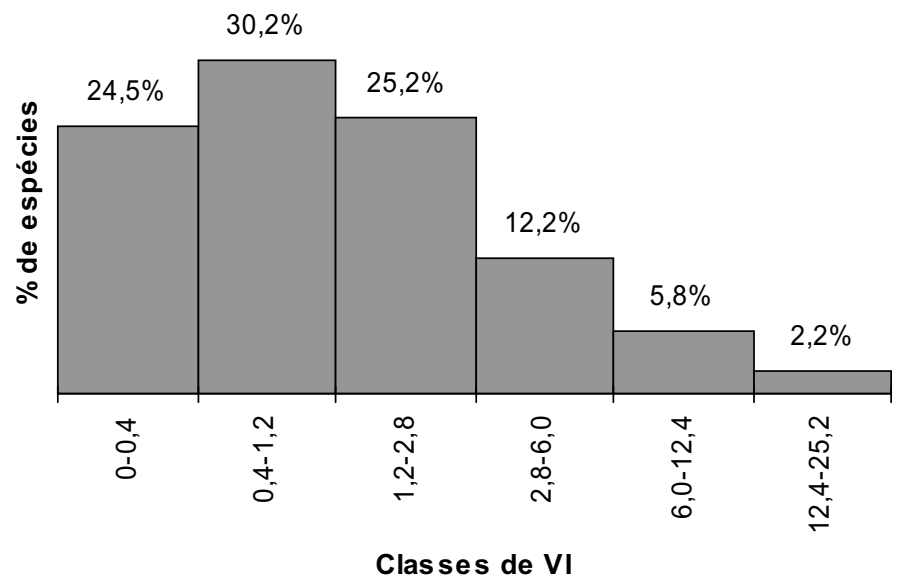

Figura 8 - Percentual de espécies nas classes de VI.

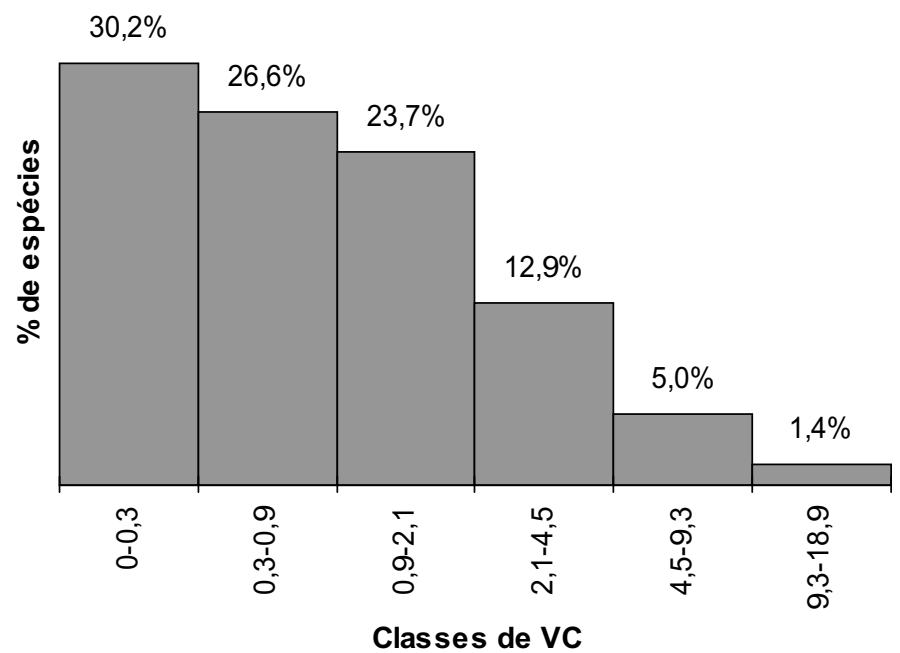

Figura 9 - Percentual de espécies nas classes de VC. 
1990; Mantovani, 1993; Melo \& Mantovani, 1994; Rodrigues, 1996; Guedes-Bruni et al., 1997; Pessoa et al., 1997). De acordo com Klein (1990), E. edulis dominava, de forma acentuada, o interior da floresta, em quase todas as associações da Mata Atlântica da região Sul do país. Apesar disto, esta espécie tem sido alvo de intenso extrativismo para a obtenção do palmito, mesmo nas unidades de conservação.

C. flexuosum, quarta posição em VI, também situou-se entre as espécies mais importantes em trechos de Mata Atlântica de São Paulo (Leitão-Filho, 1993; Mantovani, 1993; Melo \& Mantovani, 1994).

Comparando-se as 25 espécies mais importantes do presente estudo com aquelas obtidas pelo Programa Mata Atlântica (1992) (dados preliminares), que desenvolveu suas atividades em outro trecho de encosta, também situado na Estação Ecológica do Paraíso, constata-se que apenas 12 são comuns. Por outro lado, 7 das 25 espécies mais importantes levantadas por aquele Programa não foram sequer amostradas neste estudo. Tais constatações ilustram as grandes diferenças na composição florística e estrutura que podem ocorrer na Mata Atlântica, mesmo em áreas muito próximas.

Fato notável é a pequena importância, no trecho de mata estudado, do grupo constituído pelos indivíduos mortos ainda em pé. Vários trabalhos fitossociológicos realizados na Mata Atlântica e em florestas estacionais, nos estados do Rio de Janeiro e São Paulo, têm demonstrado a grande importância deste grupo (quando considerado), que ocupa, geralmente, as primeiras posições em relação ao VI (Matthes, 1980; Cavassan et al., 1984; Struffaldi-de Vuono, 1985; Rodrigues, 1986; Pagano et al., 1987; Silva, 1989; Programa Mata Atlântica, 1992; Martins, 1993).

Contrariamente, no presente estudo foram amostrados apenas 8 indivíduos mortos $(1,3 \%$ do total de 600$)$, que apresentam VI de 3,8 e ocupam a $23^{a}$ posição em importância. Tal fato poderia ser explicado pela ocorrência de fortes ventos na área, inclusive nos meses em que foram desenvolvidas as atividades de campo (maio, junho e agosto). Estes ventos, apesar de funcionarem como um fator de mortalidade, dificultariam a permanência em pé das árvores recém-mortas. Ademais, observou-se uma grande quantidade de árvores e galhos caídos, bem como uma alta proporção de árvores com injúrias mecânicas e/ou rebrotos, provavelmente em função da ação destes ventos.

Muito embora esta explicação seja bastante plausível, o grupo de árvores mortas ocupou a segunda posição em importância no trecho de mata estudado pelo Programa Mata Atlântica (1992), que situa-se na mesma Estação. Não foram levantados dados de incidência de vento nos dois trechos em questão.

Da observação da Tabela 5, nota-se que os valores de DR e FR das espécies são bastante semelhantes e proporcionais ao número de indivíduos amostrados. Desta maneira, o número de indivíduos tem um peso exagerado no cálculo do VI, tendo levado Förster (1973, apud Rosot et al., 1982) a sugerir o índice do valor de cobertura (VC no presente estudo), baseado apenas na DR e DoR (Cavassan et al., 1984).

Sendo assim, a Figura 9 apresenta o percentual de espécies para as classes geometricamente crescentes de VC, considerando-se as árvores mortas como um grupo único. Observa-se que, de uma maneira geral, é pequeno o valor de cobertura das espécies amostradas, sendo que $56,8 \%$ destas apresentam VC de até 0,9 e $93,4 \%$, de até 4,5. Considerando-se a ordenação das espécies pelos valores decrescentes de cobertura, as primeiras $41(29,5 \%)$ compõem $75,4 \%$ da soma total destes.

Apenas algumas espécies exibem certo destaque em relação ao VC. Duas espécies compõem a maior classe de cobertura, na Figura 9: Gallesia integrifolia (VC de 12,1) e Neoraputia magnifica var. magnifica $(10,3)$. Chrysophyllum lucentifolium subsp. 
lucentifolium $(8,6)$, Euterpe edulis $(8,3)$, Calycorectes sellowianus $(6,7)$, Chrysophyllum flexuosum (6,7), Micropholis crassipedicellata $(5,4)$, Pouteria filipes $(5,1)$ e Lonchocarpus filipes $(4,8)$ aparecem na segunda maior classe, de 4,5 a 9,3.

Destas espécies, N. magnifica var. magnifica, E. edulis, C. sellowianus, $C$. flexuosum e L. filipes se destacam basicamente pelos valores de DR, enquanto $G$. integrifolia, C. lucentifolium subsp. lucentifolium, M. crassipedicellata e $P$. filipes, pelos valores de DoR.

Em síntese, para todos os parâmetros fitossociológicos analisados, apenas algumas espécies apresentam certo destaque. Por outro lado, a grande maioria das espécies exibe valores baixos e semelhantes para tais parâmetros, denotando pequena contribuição de cada uma para a estrutura da mata estudada. Este padrão, característico das florestas tropicais, tem sido demonstrado em trabalhos realizados na Mata Atlântica e demais florestas brasileiras (Martins, 1989, 1993).

A Tabela 6 apresenta as famílias, em ordem decrescente de VI, com os seus respectivos números de indivíduos e espécies, estando as árvores mortas reunidas num grupo único.

Na Figura 10 são apresentadas as 10 famílias que perfazem $75,5 \%$ do número de indivíduos vivos amostrados. Destas, Myrtaceae é a que mais se destaca, com 110 indivíduos (18,6\% deste total). Seguem-se Sapotaceae (60 indivíduos), Palmae (48), Rutaceae (46), Meliaceae (44), Rubiaceae (37), Euphorbiaceae (33), Leguminosae (32: 26 da subfamília Papilionoideae e 6 de Mimosoideae), Lauraceae (19) e Bombacaceae (18). Outras 32 famílias somam os $24,5 \%$ restantes, sendo que 8 estão representadas por um único indivíduo.

Tabela 6 - Famílias amostradas na Estação Ecológica Estadual do Paraíso, mun. de Cachoeiras de Macacu, RJ, em ordem decrescente de VI. N - número de indivíduos; Spp - número de espécies; VI - valor de importância.

\begin{tabular}{llll}
\hline Famílias & $\mathrm{N}$ & Spp & $\mathrm{VI}$ \\
\hline SAPOTACEAE & 60 & 14 & 43,88 \\
MYRTACEAE & 110 & 27 & 40,30 \\
RUTACEAE & 46 & 2 & 18,88 \\
MELIACEAE & 44 & 6 & 18,68 \\
PALMAE & 48 & 2 & 16,21 \\
MORACEAE & 13 & 6 & 14,11 \\
EUPHORBIACEAE & 33 & 4 & 13,87 \\
LEGUMINOSAE & 32 & 5 & 13,79 \\
RUBIACEAE & 37 & 9 & 13,61 \\
PHYTOLACCACEAE & 4 & 1 & 12,88 \\
BOMBACACEAE & 18 & 3 & 11,41 \\
LAURACEAE & 19 & 14 & 8,81 \\
NYCTAGINACEAE & 16 & 4 & 8,58 \\
MYRISTICACEAE & 13 & 2 & 7,89 \\
HIPPOCRATEACEAE & 17 & 2 & 5,91 \\
MONIMIACEAE & 10 & 1 & 5,31 \\
APOCYNACEAE & 7 & 3 & 4,77 \\
SAPINDACEAE & 4 & 3 & 4,30 \\
MORTAS & 8 & - & 3,91 \\
LECYTHIDACEAE & 3 & 1 & 3,56 \\
CLUSIACEAE & 8 & 2 & 3,10 \\
& & & Rodriguésia $51(78 / 115): 69-112.2000$
\end{tabular}


Composição florística e estrutura do componente arbóreo de um trecho de Mata Atlântica na

Estação Ecológica Estadual do Paraíso, Cachoeiras de Macacu, Rio de Janeiro, Brasil

\begin{tabular}{llll}
\hline Famílias & N & Spp & VI \\
ICACINACEAE & 7 & 1 & 2,59 \\
ULMACEAE & 3 & 2 & 2,23 \\
MALPIGHIACEAE & 4 & 1 & 1,96 \\
ANNONACEAE & 4 & 3 & 1,76 \\
PROTEACEAE & 1 & 1 & 1,62 \\
ELAEOCARPACEAE & 2 & 1 & 1,55 \\
ERYTHROXYLACEAE & 4 & 1 & 1,54 \\
FLACOURTIACEAE & 4 & 2 & 1,53 \\
BURSERACEAE & 1 & 1 & 1,29 \\
VIOLACEAE & 2 & 1 & 1,24 \\
MELASTOMATACEAE & 2 & 1 & 1,19 \\
SABIACEAE & 1 & 1 & 1,15 \\
CHRYSOBALANACEAE & 2 & 1 & 0,92 \\
OLACACEAE & 1 & 1 & 0,88 \\
COMBRETACEAE & 2 & 1 & 0,84 \\
CONNARACEAE & 2 & 1 & 0,76 \\
MYRSINACEAE & 2 & 1 & 0,76 \\
BIGNONIACEAE & 2 & 2 & 0,75 \\
CARICACEAE & 1 & 1 & 0,54 \\
SOLANACEAE & 1 & 1 & 0,38 \\
CELASTRACEAE & 1 & 1 & 0,37 \\
BORAGINACEAE & 1 & 1 & 0,37 \\
\hline
\end{tabular}

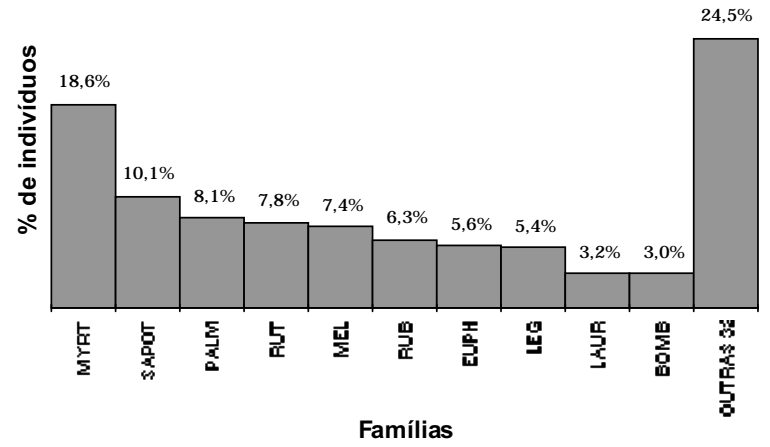

Figura 10 - Distribuição do número de indivíduos (\%) por família, perfazendo 75,5\% do total. Myrt. - Myrtaceae; Sapot. - Sapotaceae; Palm. - Palmae; Rut. - Rutaceae; Mel. - Meliaceae; Rub. - Rubiaceae; Euph. - Euphorbiaceae; Leg. - Leguminosae; Laur. - Lauraceae; e Bomb. - Bombacaceae.

Em Myrtaceae, as maiores contribuições são de Calycorectes sellowianus (29 indivíduos) e Eugenia tinguyensis (17); em Sapotaceae, de Chrysophyllum flexuosum (32); em Palmae, de Euterpe edulis, com 45 dos 48 indivíduos amostrados para a família; em Rutaceae, de Neoraputia magnifica var. magnifica, com 41 dos 46 indivíduos da família; em Meliaceae, de Guarea kunthiana (19) e
G. macrophylla subsp. tuberculata (12); em Rubiaceae, de Psychotria subspathacea (20); em Euphorbiaceae, de Pausandra megalophylla (17) e Senefeldera verticillata (13); em Leguminosae, de Lonchocarpus filipes (21); e em Bombacaceae, de Quararibea turbinata, com 16 dos 18 indivíduos da família.

De acordo com Richards (1981), a 
dominância por família, que consiste na preponderância numérica de espécies de uma mesma família, parece ser uma característica comum de florestas tropicais. Embora não se possa falar numa nítida dominância de Myrtaceae na mata estudada, esta família apresenta grande destaque em relação às demais (Figura 10), possuindo quase o dobro de indivíduos de Sapotaceae, segunda em número de indivíduos.

Na Figura 11 são indicadas as 13 famílias que somam $73,2 \%$ do número de espécies. Myrtaceae apresenta grande destaque, com 27 espécies (19,6\% do total amostrado), seguida por Sapotaceae e Lauraceae, com 14 espécies cada uma. Já com um número mais reduzido de espécies, seguem-se Rubiaceae, com 9; Meliaceae e Moraceae, com 6; Leguminosae, com 5 (4 da subfamília Papilionoideae e 1 de Mimosoideae); Euphorbiaceae e Nyctaginaceae, com 4; e Bombacaceae, Apocynaceae, Sapindaceae e Annonaceae, cada uma com 3. Outras 29 famílias perfazem os $26,8 \%$ restantes, sendo que 21 estão representadas por apenas 1 espécie.

Em Myrtaceae, destacam-se os gêneros Eugenia (11 espécies) e Myrcia (5); em Sapotaceae, Pouteria (8); e em Lauraceae, Ocotea (6).

Os estudos fitossociológicos realizados em várias formações da Mata Atlântica, nos estados da Paraíba, Bahia, Espírito Santo, Rio de Janeiro e São Paulo, têm indicado a família Myrtaceae como aquela de maior riqueza em espécies (Silva \& Leitão-Filho, 1982; Mori et al., 1983; Guedes, 1988; Mantovani et al., 1990; Leitão-Filho, 1993; Mantovani, 1993; Melo \& Mantovani, 1994; Oliveira et al., 1995; Rodrigues, 1996; Guedes-Bruni et al., 1997; Moreno et al., 1998) ou como uma das mais ricas (Mayo \& Fevereiro, 1982; Guedes, 1988; Peixoto \& Gentry, 1990; Programa Mata Atlântica, 1992; Pessoa et al., 1997).

De acordo com Peixoto (1991/92), na região neotropical, esta riqueza em espécies de Myrtaceae está restrita à costa brasileira, sendo, no entanto, típica de florestas da Austrália e Madagascar.

Das outras famílias destacadas na Figura 11, Sapotaceae, Lauraceae, Rubiaceae, Meliaceae, Moraceae, Leguminosae, Euphorbiaceae, Sapindaceae e Annonaceae também têm sido frequentemente relacionadas, nos estudos acima citados, entre aquelas com maior número de espécies.

As 12 famílias que somam 75,3\% do VI são mostradas na Figura 12. Apresentam nítido destaque as famílias Sapotaceae e Myrtaceae, com VIs de 43,9 e 40,3, respectivamente. Com valores de importância bem menores e gradativamente decrescentes, seguem-se Rutaceae $(18,9)$, Meliaceae $(18,7)$, Palmae $(16,2)$, Moraceae $(14,1)$, Euphorbiaceae $(13,9)$,

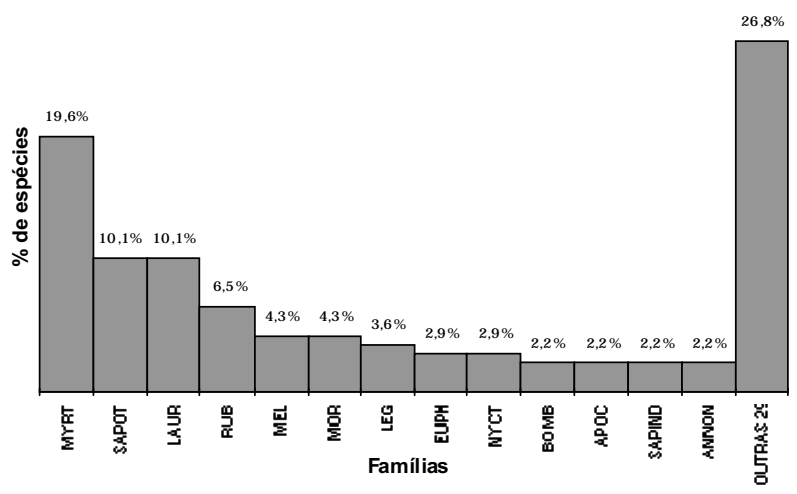

Figura 11 - Distribuição do número de espécies (\%) por família, perfazendo 73,1\% do total. Myrt. - Myrtaceae; Sapot. - Sapotaceae; Laur. - Lauraceae; Rub. - Rubiaceae; Mel. - Meliaceae; Mor. - Moraceae; Leg. - Leguminosae; Euph. Euphorbiaceae; Nyct. - Nyctaginaceae; Bomb. - Bombacaceae; Apoc. - Apocynaceae; Sapind. - Sapindaceae; e Annon. Annonaceae. 


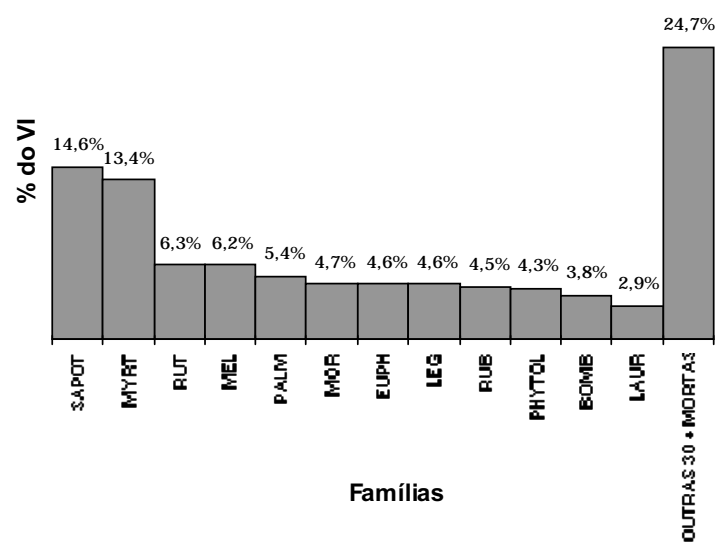

Figura 12 - Distribuição do valor de importância (\%) por família, perfazendo 75,3\% do total. Sapot. - Sapotaceae; Myrt. - Myrtaceae; Rut. - Rutaceae; Mel. - Meliaceae; Palm. - Palmae; Mor. - Moraceae; Euph. - Euphorbiaceae; Leg. Leguminosae; Rub. - Rubiaceae; Phytol. - Phytolaccaceae; Bomb. - Bombacaceae; e Laur. - Lauraceae.

Leguminosae $(13,8)$, Rubiaceae $(13,6)$, Phytolaccaceae $(12,9)$, Bombacaceae $(11,4)$ e Lauraceae $(8,8)$. Outras 30 famílias e o grupo das árvores mortas somam os $24,7 \%$ restantes do VI.

Algumas espécies contribuem decisivamente ou respondem sozinhas pela importância de suas respectivas famílias. É o caso, por exemplo, de Neoraputia magnifica var. magnifica (Rutaceae), Euterpe edulis (Palmae) e Gallesia integrifolia (Phytolaccaceae).

Das famílias destacadas na Figura 12, Myrtaceae, Rutaceae, Meliaceae, Palmae, Euphorbiaceae, Leguminosae e Rubiaceae têm nos seus valores de densidade e frequência relativas as maiores contribuições na composição do VI, ao passo que para Sapotaceae, Moraceae, Phytolaccaceae e, em menor escala, Bombacaceae é a dominância relativa que mais contribui (em Phytolaccaceae, a DoR compõe $88,9 \%$ do VI). Já no caso de Lauraceae, ocorre uma contribuição mais uniforme destes parâmetros.

Estas contribuições diferenciadas da DR, FR e DoR na composição do valor de importância traduzem tendências no sentido de diferentes estratégias de ocupação do ambiente por parte destas famílias, pelo menos na área do presente estudo.

Neste sentido, apesar de apresentar apenas pouco mais da metade dos indivíduos de Myrtaceae, o que condiciona valores de DR e FR bem inferiores, Sapotaceae é a família de maior importância, pois o grande porte de várias de suas árvores lhe garantem um altíssimo valor de DoR.

Das famílias em destaque na Figura 12, Sapotaceae, Myrtaceae, Palmae, Euphorbiaceae, Leguminosae, Rubiaceae, Bombaceae e Lauraceae têm sido frequentemente relacionadas entre as de maior VI para a Mata Atlântica dos estados do Rio de Janeiro e São Paulo, enquanto Meliaceae e Moraceae aparecem com menor frequência (Silva \& Leitão-Filho, 1982; Guedes, 1988; Mantovani et al., 1990; Programa Mata Atlântica, 1992; Leitão-Filho, 1993; Mantovani, 1993; Melo \& Mantovani, 1994; Guedes-Bruni et al., 1997; Pessoa et al., 1997). Por outro lado, Rutaceae e Phytolaccaceae não foram citadas nestes estudos, embora a primeira destas famílias seja indicada como uma das mais importantes nas florestas estacionais de São Paulo (Matthes, 1980; Cavassan et al., 1984; Bertoni et al., 1988; Cesar, 1988; Martins, 1993). Já Phytolaccaceae apresenta menor importância nesta formação (Cavassan et al., 1984; Bertoni et al., 1988).

\section{Diversidade e equabilidade}

O índice de diversidade de Shannon (H') para o trecho de mata estudado é de 4,20 e a equabilidade (J), de 0,85 . 
Segundo Knight (1975, apud Martins, 1993), altos índices de diversidade de florestas temperadas variam de 2,0 a 3,0, enquanto os índices de diversidade de espécies arbóreas com 2,5 cm ou mais de DAP para florestas da Ilha de Barro Colorado, no Panamá, variaram de 3,83 até 5,85 , com uma média de 4,8 para todos os estandes estudados, representando "the highest ever reported for any community".

Martins (1993), com base em diversos trabalhos, apresentou os índices de diversidade relativos a várias florestas brasileiras. Para as florestas amazônicas, estes índices situaramse entre 2,63 e 4,76; para as florestas atlânticas (Mata Atlântica), entre 3,61 e 4,07 (não foram considerados os índices calculados separadamente para as megafanerófitas, mesofanerófitas e arvoretas, a partir dos dados de Veloso \& Klein (1957), referentes ao município de Brusque, Santa Catarina); e para as florestas do interior de São Paulo, entre 3,16 e 3,63.

Os estudos realizados na Mata Atlântica dos estados do Rio de Janeiro (Davis, 1945, apud Martins, 1993; Guedes, 1988; Programa Mata Atlântica, 1992; Rodrigues, 1996; Guedes-Bruni et al., 1997; Pessoa et al., 1997; Sampaio, 1997; Delamônica et al., inéd.), São Paulo (Silva \& Leitão-Filho, 1982; Mantovani et al., 1990; Leitão-Filho, 1993; Mantovani, 1993; Melo \& Mantovani, 1994) e Santa Catarina (Veloso \& Klein, 1957, apud Silva, 1980) indicaram que o índice de Shannon variou de 1,69 a 4,4, ambos os casos no Rio de Janeiro. Deste modo, constata-se que o valor encontrado no presente trabalho $\left(\mathrm{H}^{\prime}=4,20\right)$ é um dos mais altos já registrados para a Mata Atlântica.

Os maiores valores encontrados nestes estudos referem-se a um gradiente ao longo de uma encosta $\left(\mathrm{H}^{\prime}=4,4\right.$; Programa Mata Atlântica, 1992), à amostragem de um trecho de encosta, abrangendo uma grande área com prováveis variações topográficas e sucessionais (4,36; Rodrigues, 1996), à soma dos dados de três unidades de amostragem algo distintas dos pontos de vista topográfico e sucessional (apesar de muito próximas) $(4,31$; Leitão-Filho, 1993) e à análise conjunta do componente dominante e do sub-bosque $(4,31$; Mantovani, 1993).

No outro extremo, baixos índices de diversidade estão associados a características edáficas e perturbação antrópica $\left(\mathrm{H}^{\prime}=1,84\right.$; Guedes, 1988), à pesada poluição atmosférica (2,14; Leitão-Filho, 1993) e a estágios iniciais da sucessão secundária $(2,46$ e 2,68; Delamônica et al., inéd.).

A diversidade é um reflexo de dois parâmetros, que são a riqueza em espécies e a equabilidade, esta relacionada com a contribuição numérica relativa de cada espécie. Neste sentido, de acordo com Mantovani (1993), vários são os fatores que podem interferir no índice de diversidade, ressaltandose o método de amostragem e o critério de inclusão dos indivíduos. Ainda segundo este autor, a utilização de critérios de inclusão que favoreçam a amostragem de componentes do sub-bosque interfere diretamente no índice de Shannon, uma vez que considera, como elementos semelhantes, populações com indivíduos de tamanhos excepcionalmente diferentes.

No presente trabalho, constata-se que a riqueza em espécies (138) e a equabilidade (J $=0,85)$ contribuem igualmente para o alto índice de diversidade encontrado $\left(H^{\prime}=4,20\right)$.

\section{Estratificação}

A distribuição de frequência das classes de altura é apresentada na Figura 13. Pode-se observar a ocorrência de dois estratos arbóreos, praticamente contínuos, além de árvores emergentes. $\mathrm{O}$ estrato inferior, situado entre 1,8 e $18 \mathrm{~m}$, é composto pela grande maioria dos indivíduos vivos amostrados $(89,4 \%$ do total). O estrato superior, formado por árvores de 20 a 30 m, não chega a constituir um dossel fechado, acima do qual sobressaem os emergentes que podem atingir $45 \mathrm{~m}$ de altura. Este dossel descontínuo, já constatado durante as atividades de campo, está associado a dois fatores, que são a declividade acentuada de 


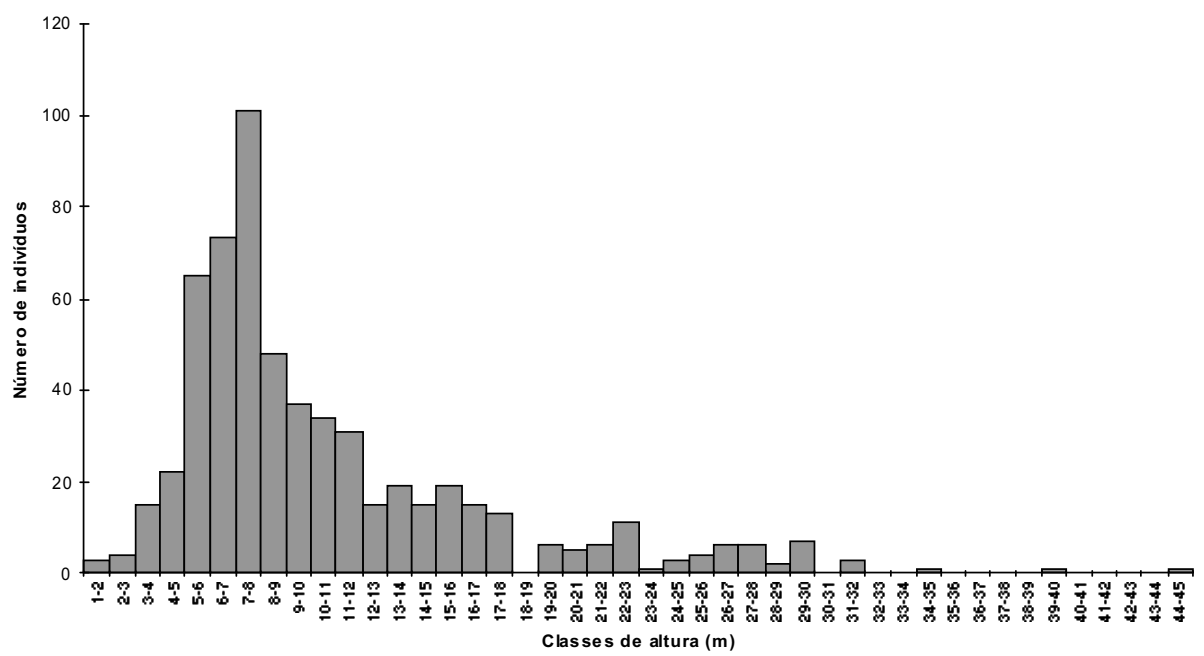

Figura 13 - Distribuição de frequência das classes de altura das árvores amostradas na Estação Ecológica Estadual do Paraíso, Cachoeiras de Macacu, RJ.

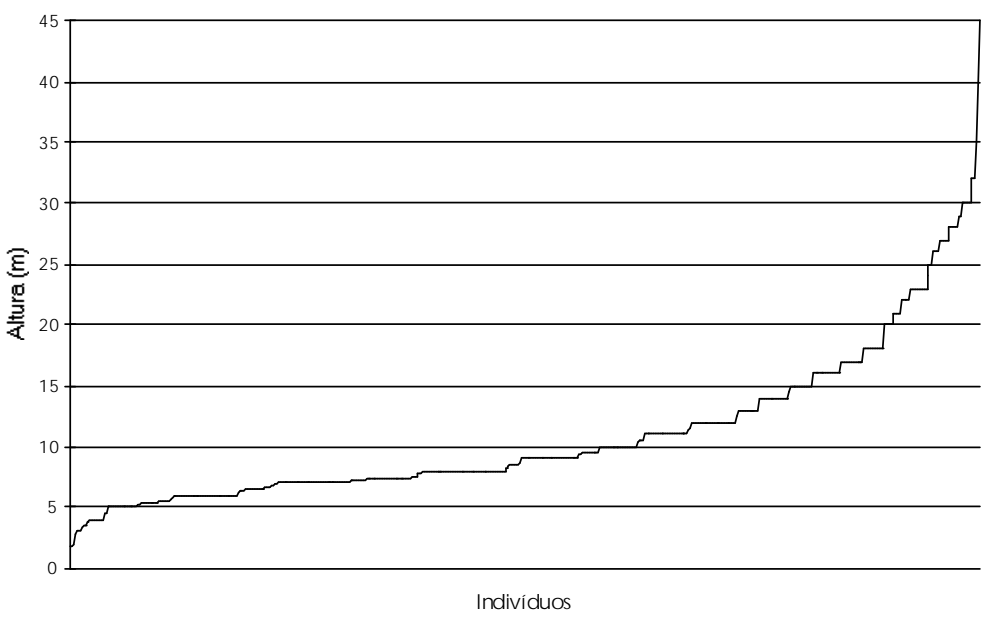

Figura 14 - Curva diferencial de altura das árvores amostradas na Estação Ecológica Estadual do Paraíso, Cachoeiras de Macacu, RJ.

certos trechos da mata, condicionando uma distribuição escalonada das copas, e a ocorrência de muitos afloramentos rochosos em outros, dificultando o desenvolvimento de árvores de maior porte.

Noventa espécies $(65,2 \%$ do total) ocorrem exclusivamente no estrato inferior. Destas, Euterpe edulis (45 indivíduos), Neoraputia magnifica var. magnifica (41), Chrysophyllum flexuosum (32), Calycorectes sellowianus (29), Lonchocarpus filipes (21), Psychotria subspathacea (20), Guarea kunthiana (19), Pausandra megalophylla
(17), Eugenia tinguyensis (17) e Salacia grandifolia (16) são as mais conspícuas, somando 48,6\% dos indivíduos amostrados neste estrato.

Ademais, é interessante mencionar que, das 10 espécies mais importantes para o trecho de mata estudado (Tabela 5), 8 são exclusivas do estrato inferior.

Das 48 espécies que atingem o estrato superior $(34,8 \%$ do total), 6 apresentam indivíduos emergentes: Chrysophyllum lucentifolium subsp. lucentifolium $(45 \mathrm{~m})$, Cariniana legalis (40), Micropholis 
crassipedicellata (35), Gallesia integrifolia (32), Matayba sp. (32) e Diploon cuspidatum (32).

A nível de família, observa-se também um comportamento diferenciado em relação aos estratos, no que se refere à distribuição de suas espécies e indivíduos. Neste sentido, considerando-se as famílias destacadas na composição do VI (Figura 12), Myrtaceae, Rutaceae, Meliaceae, Palmae, Rubiaceae e Lauraceae ocorrem exclusivamente ou preferencialmente no estrato inferior, enquanto Moraceae, Phytolaccaceae e Bombacaceae são características do estrato superior (Phytolaccaceae apresenta um indivíduo emergente). Já Sapotaceae, Euphorbiaceae e Leguminosae estão mais equitativamente distribuídas em ambos os estratos (Sapotaceae também apresenta indivíduos emergentes).

A Figura 14 mostra a curva diferencial de alturas. O limite entre os dois estratos arbóreos está representado, nesta curva, por uma pequena faixa vertical entre 18 e $20 \mathrm{~m}$. A grande quantidade de indivíduos do estrato inferior é traduzida pela pequena inclinação da curva diferencial, principalmente entre 5 e 12 $\mathrm{m}$, enquanto que a grande inclinação na faixa de 20 a $30 \mathrm{~m}$ é reflexo do número relativamente menor de árvores que constituem o dossel. Os poucos indivíduos emergentes estão representados por uma faixa praticamente vertical, acima de $30 \mathrm{~m}$.

Através da comparação das Figuras 13 e 14, observa-se que a distribuição de frequência das classes de altura permite uma melhor individualização dos estratos, enquanto que a curva diferencial sugere uma distribuição mais contínua de alturas. Apesar disto, é possível visualizar nesta os estratos definidos a partir da primeira.

\section{Distribuição de frequência das classes de diâmetro e altura}

As distribuições de frequência das classes de diâmetro de todas as árvores vivas amostradas e para as espécies com um mínimo de 15 indivíduos estão representadas nas
Figuras 15 a 25. A distribuição de frequência das classes de altura do estipe de Euterpe edulis encontra-se na Figura 26.

Observa-se na Figura 15 uma grande concentração de indivíduos na primeira classe de diâmetro, que contém $82,1 \%$ do total de indivíduos vivos amostrados. Da segunda a sexta classe, ocorre uma diminuição gradual do número de indivíduos e da sétima classe em diante, o que corresponde a diâmetros a partir de 98,0 cm, registra-se a ocorrência de apenas algumas árvores. Estas pertencem às espécies Chrysophyllum lucentifolium subsp. lucentifolium (DAP de 160,0 cm), Gallesia integrifolia (157,4), Micropholis crassipedicellata $(128,8)$, Ficus clusiifolia $(113,5), F$. pulchella $(113,0)$ e Chorisia speciosa $(112,0)$.

A grande concentração de indivíduos na primeira classe está relacionada, em parte, ao método utilizado para o cálculo do intervalo de classe, que leva em consideração a amplitude total de diâmetros. A grande amplitude apresentada pelos indivíduos amostrados, motivada pela presença daqueles poucos com diâmetros muito elevados, conduziu a um intervalo de classe muito amplo e à consequente concentração exagerada, não só de indivíduos como também de espécies, na primeira classe. Em relação às espécies, 71 (51,4\% do total) estão restritas a esta classe.

Apesar de possuir a forma de um ' $\mathrm{J}$ ' invertido, a distribuição apresentada na Figura 15 não se mostra balanceada (distribuição na qual o fator de redução do número de indivíduos de uma classe para a seguinte é constante), embora seja quase regra que a distribuição dos diâmetros dos troncos das árvores das florestas tropicais apresente aproximadamente esta característica (Heinsdijk, 1965).

De acordo com Daubenmire (1968), para árvores e arbustos com câmbio ativo, o diâmetro do tronco é um indicador razoavelmente seguro da idade relativa, desde que as classes de tamanho não sejam divididas muito finamente, nem interpretadas muito de perto, e que se tenha em mente que a mesma 


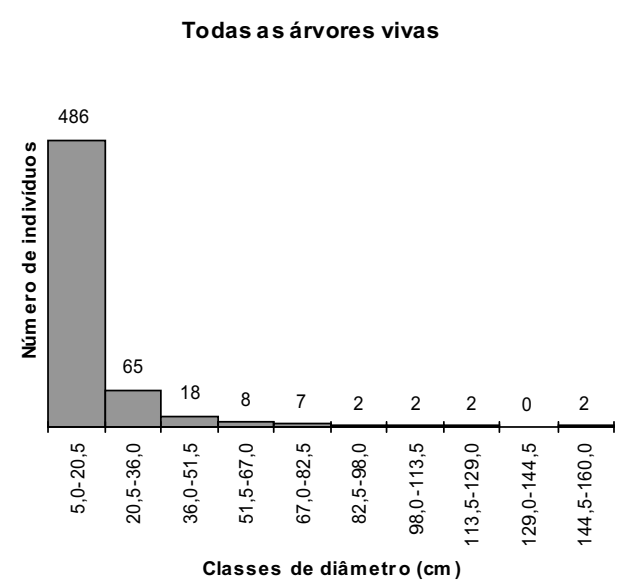

Figura 15 - Distribuição de frequência das classes de diâmetro de todas as árvores vivas amostradas na Estação Ecológica Estadual do Paraíso, Cachoeiras de Macacu, RJ.

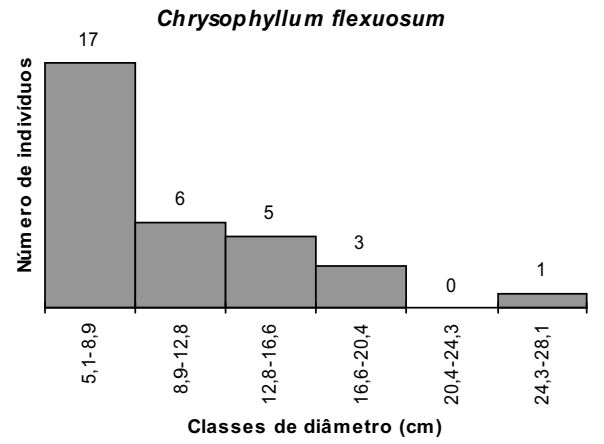

Figura 17 - Distribuição de frequência das classes de diâmetro dos indivíduos de Chrysophyllum flexuosum.

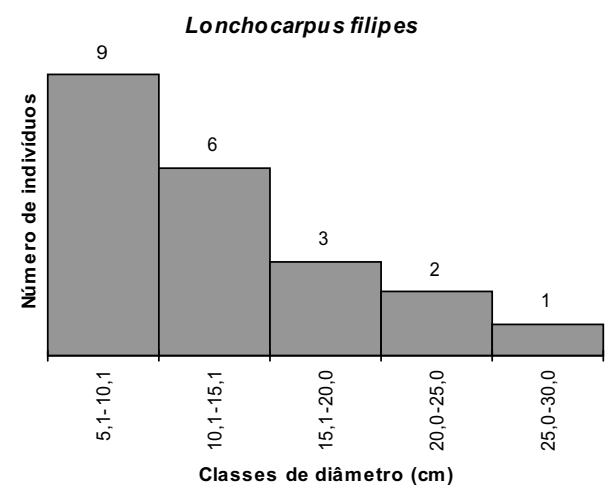

Figura 19 - Distribuição de frequência das classes de diâmetro dos indivíduos de Lonchocarpus filipes.

Rodriguésia 51(78/115): 69-112. 2000

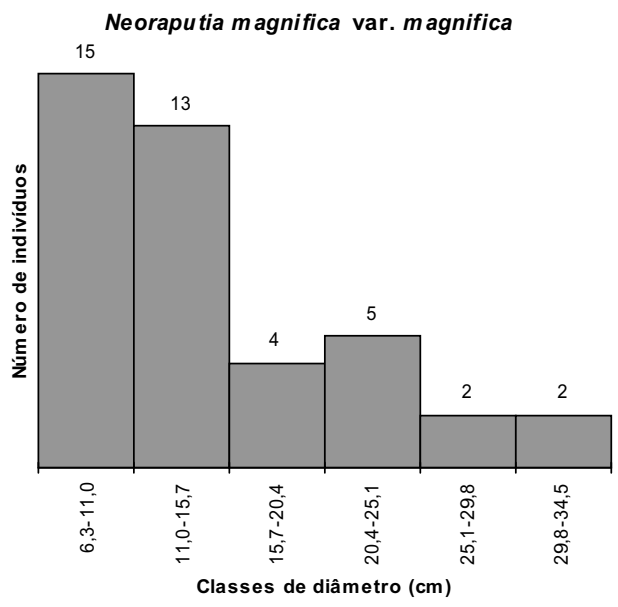

Figura 16 - Distribuição de frequência das classes de diâmetro dos indivíduos de Neoraputia magnifica var. magnifica.

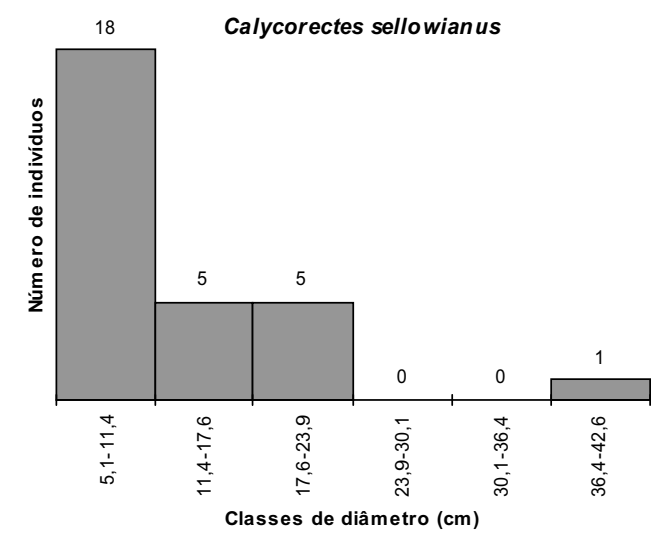

Figura 18 - Distribuição de frequência das classes de diâmetro dos indivíduos de Calycorectes sellowianus.

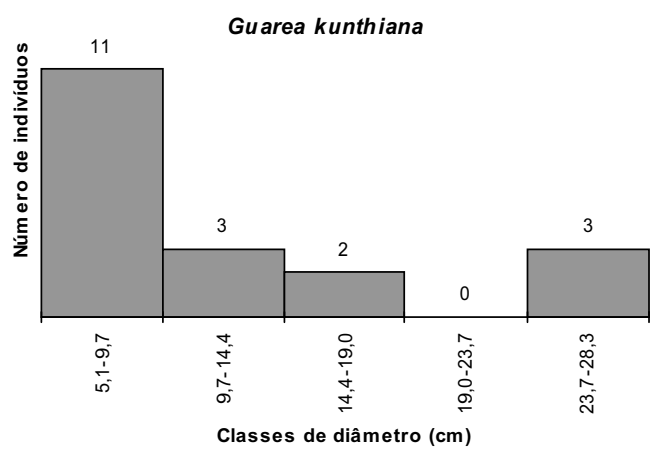

Figura 20 - Distribuição de frequência das classes de diâmetro dos indivíduos de Guarea kunthiana. 


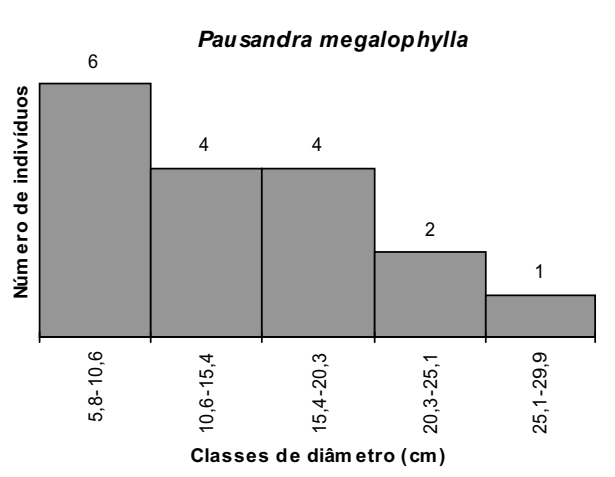

Figura 21 - Distribuição de frequência das classes de diâmetro dos indivíduos de Pausandra megalophylla.

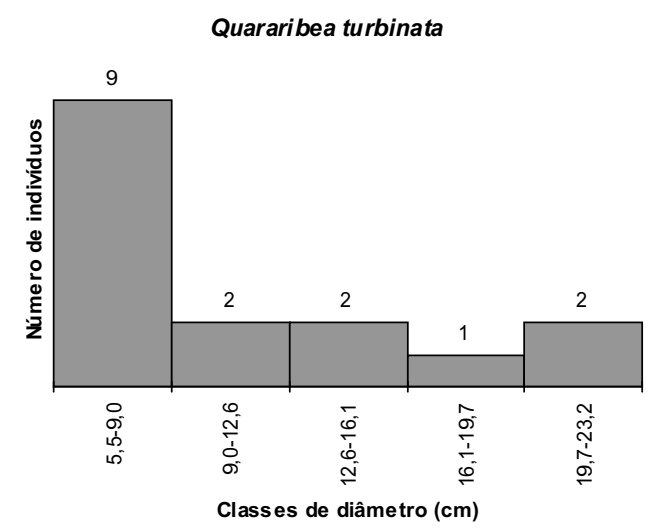

Figura 23 - Distribuição de frequência das classes de diâmetro dos indivíduos de Quararibea turbinata.

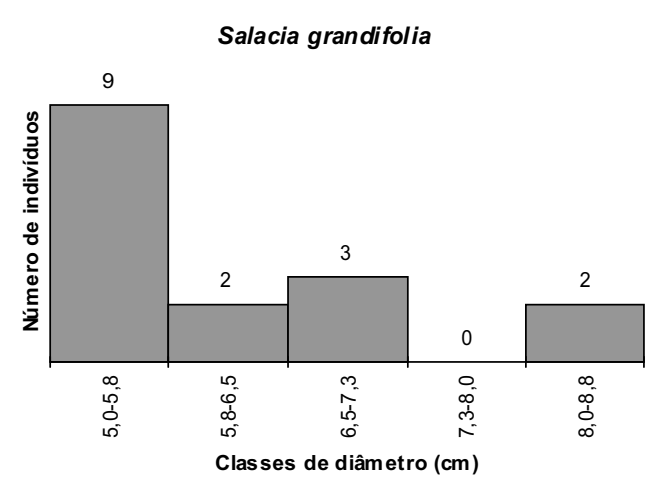

Figura 25 - Distribuição de frequência das classes de diâmetro dos indivíduos de Salacia grandifolia.

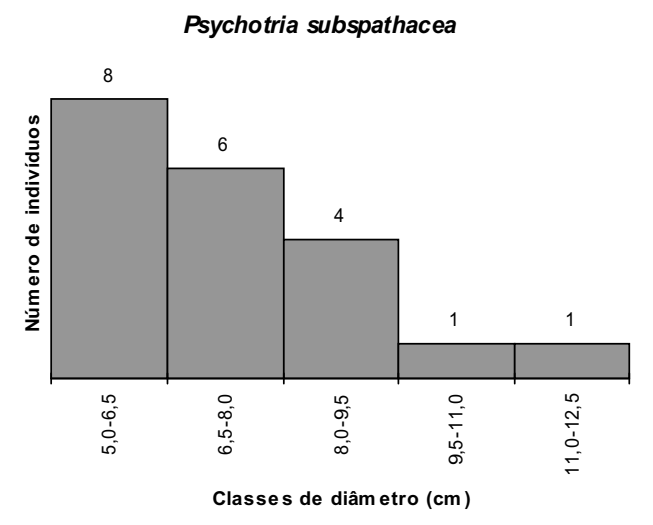

Figura 22 - Distribuição de frequência das classes de diâmetro dos indivíduos de Psychotria subspathacea.

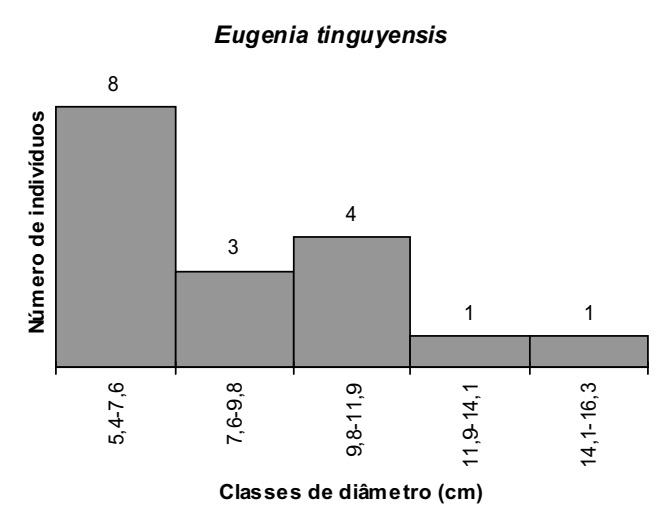

Figura 24 - Distribuição de frequência das classes de diâmetro dos indivíduos de Eugenia tinguyensis.

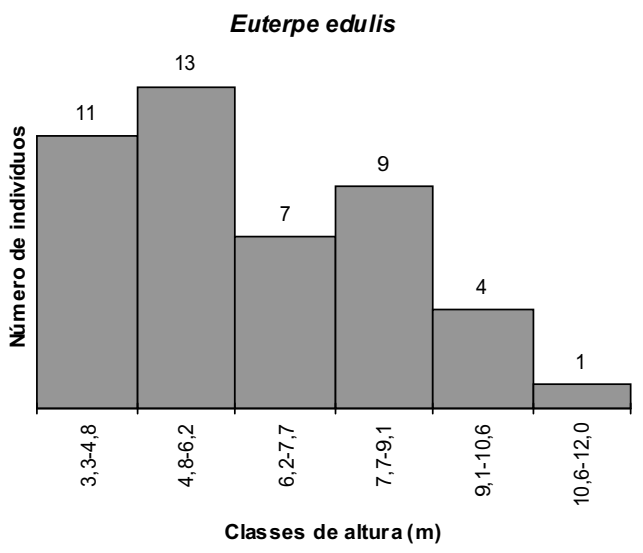

Figura 26 - Distribuição de frequência das classes de altura do estipe dos indivíduos de Euterpe edulis.

Rodriguésia 51(78/115): 69-112. 2000 
amplitude de tamanhos em espécies diferentes não indica amplitudes equivalentes de idade. Embora seja fácil demostrar que a idade em anos é apenas grosseiramente proporcional ao diâmetro, o autor informa que uma série gradual de tamanhos tem aproximadamente $o$ mesmo significado sucessional de uma série gradual de idades, considerando-se cada espécie individualmente.

Ainda segundo Daubenmire (1968), se uma comunidade clímax é definida como aquela que mostra ter posse permanente do habitat, esperar-se-ía uma série completa de classes de idade para cada espécie, visto que para cada planta que morre ou avança em idade uma outra ligeiramente mais jovem deve estar disponível para substituí-la. Quando a série de classes de idade é interrompida ou truncada em qualquer um dos extremos, o ciclo de vida não está se completando e a espécie geralmente não pode ser considerada em equilíbrio no habitat. Populações em equilíbrio apresentam distribuição de frequência das classes de idade (ou diâmetro) aproximadamente balanceada.

A presença de regeneração das espécies arbóreas dominantes indica a maturidade de uma floresta, embora a grande riqueza em espécies e a ausência de uma clara dominância na maioria das florestas tropicais dificultem a aplicação efetiva deste critério (Hartshorn, 1980).

O estudo da dinâmica populacional das espécies arbóreas dominantes ou importantes pode ajudar na diferenciação de florestas maduras (em clímax) e secundárias avançadas (Gómez-Pompa et al., 1974, apud Hartshorn, 1980).

Com o objetivo de se obterem subsídios para a avaliação do estágio sucessional da mata estudada, foram elaborados os histogramas de frequência das classes de diâmetro (e de altura do estipe, no caso de $E$. edulis) dos indivíduos das espécies numericamente preponderantes. Estas espécies, 11 no total, estão entre as 16 de maior VI para a área.
Destas, Neoraputia magnifica var. magnifica (Figura 16), Chrysophyllum flexuosum (Figura 17), Lonchocarpus filipes (Figura 19), Pausandra megalophylla (Figura 21) e Psychotria subspathacea (Figura 22) apresentam, aproximadamente, distribuições balanceadas.

Já Calycorectes sellowianus (Figura 18), Guarea kunthiana (Figura 20), Quararibea turbinata (Figura 23), Eugenia tinguyensis (Figura 24) e Salacia grandifolia (Figura 25) mostram distribuições um pouco mais irregulares.

Apesar disto, evidencia-se, pela análise das Figuras 16 a 25, que todas as espécies consideradas apresentam maior número de indivíduos na primeira classe de diâmetro e que, apesar de desvios maiores ou menores, existe uma tendência geral de diminuição deste número ao longo das classes subsequentes. Este comportamento das referidas distribuições, que tendem a apresentar a forma de um ' $J$ ' invertido, é típico de espécies com regeneração abundante e estrutura populacional estável.

A análise da Figura 26 mostra uma distribuição aparentemente irregular de frequência das classes de altura do estipe de Euterpe edulis. O número reduzido de indivíduos na primeira classe está relacionado ao critério de inclusão utilizado neste estudo (DAP ${ }^{3}$ a $5 \mathrm{~cm}$ ): alguns indivíduos com altura do estipe correspondente à primeira classe (entre 3,3 e 4,8 m) não foram amostrados por apresentarem DAP inferior a $5 \mathrm{~cm}$. Por este motivo, considera-se que para esta espécie também existe uma tendência à redução dos indivíduos ao longo das classes de altura, traduzindo uma regeneração abundante e uma estrutura populacional estável (muito embora tenham sido observados alguns poucos indivíduos cortados).

De fato, apesar do critério de inclusão utilizado ter excluído da análise (e, desta maneira, a possibilidade de quantificação) uma parcela importante da regeneração das populações de E. edulis e demais espécies 
consideradas acima, observou-se, durante as atividades de campo, grande quantidade de plântulas e indivíduos jovens destas espécies.

Em estudo realizado na Mata Atlântica de Teresópolis, Rio de Janeiro (Veloso, 1945), $Q$. turbinata foi citada como sendo característica do clímax. C. flexuosum, $Q$. turbinata e E. edulis foram classificadas por Mantovani (1993), em um trecho de Mata Atlântica na Estação Ecológica da JuréiaItatins, São Paulo, como espécies do clímax, embora a primeira e a terceira tenham sido classificadas, respectivamente, como pioneira e secundária inicial, em trechos da Mata Atlântica de Cubatão, São Paulo (Leitão-Filho, 1993). Como mencionado anteriormente, na área em que se desenvolveu o presente estudo, estas espécies apresentam vasta regeneração no interior da mata, sendo portanto consideradas do clímax (ou secundárias tardias, de acordo com a classificação adotada por Leitão-Filho (1993)).

Outras espécies, classificadas por Mantovani (1993) como do clímax, ocorrem na área com indivíduos adultos de grande porte: Virola oleifera, Ficus pulchella e Brosimum glaziovii. Caracterizada como secundária tardia (Leitão-Filho, 1993), Micropholis crassipedicellata se faz representar por um indivíduo emergente.

Os aspectos abordados acima sugerem que a mata estudada encontra-se, possivelmente, em clímax ou em estágio muito próximo deste. Tal suposição é válida, entretanto, quando se considera a mata em seu conjunto, uma vez que florestas tropicais maduras são na realidade um mosaico de estágios sucessionais (Hartshorn, 1980). A ocorrência de um dossel não contínuo, com o consequente aumento da luminosidade em alguns trechos do interior da mata, tem, certamente, grande importância neste processo dinâmico.

As informações obtidas no início do desenvolvimento deste estudo não indicaram a ocorrência de desmatamentos ou cortes seletivos mais intensos na área escolhida (pelo menos nos últimos 60 anos), nem constatouse, durante as atividades de campo, qualquer sinal de tais atividades (com exceção dos poucos indivíduos cortados de E. edulis). Quanto à possibilidade de qualquer tipo de exploração em épocas anteriores, torna-se difícil a sua constatação, pela ausência de registros.

Nos dias atuais, o maior problema da Estação Ecológica do Paraíso não é a utilização direta de seus recursos vegetais e sim a grande pressão exercida sobre a fauna. Caçadores e passarinheiros estão permanentemente em atividade na área da Estação, estimulados pela ausência de uma fiscalização eficiente, sendo comum encontrarem-se grandes acampamentos e/ou restos de armadilhas usadas na caça (principalmente o 'toco' ou 'trabuco').

Esta degradação de mamíferos e aves tem, obviamente, reflexos danosos importantes na vegetação, uma vez que nas florestas tropicais um grande percentual de espécies tem nestes animais seus vetores de dispersão de diásporos (Hilty, 1980; Janzen, 1980; Morellato \& Leitão-Filho, 1992, entre outros).

$\mathrm{Na}$ realidade, o grande problema da Estação do Paraíso é o mesmo da maioria das unidades de conservação do país: situação fundiária e administrativo-institucional calamitosa. Apesar de ter sido criada em março de 1987, a Estação não teve até hoje o seu plano diretor aprovado (apesar de redigido em 1989), além de carecer de um quadro de funcionários (Henrique F. Martins, com. pess.). É fundamental que no Brasil a conservação da Mata Atlântica e demais ecossistemas seja encarada de modo mais sério e responsável, tanto pelas autoridades como pelos diversos segmentos da sociedade, para que não se condene à extinção, em futuro próximo, um número incalculável de organismos vivos.

\section{CONCLUSÕES}

Considerando-se os valores médios de temperatura e precipitação de 1979 a 1988, 
evidencia-se para a área estudada a inexistência de período seco para as plantas ou déficit hídrico.

Esta área está contida numa associação composta por Cambissolo, afloramentos rochosos e solo litólico, sendo que os perfis analisados correspondem ao primeiro membro desta associação. As correlações observadas sugerem que os processos de perda de cátions básicos e enriquecimento em alumínio estejam controlando o $\mathrm{pH}$ nestes perfis. A relação $\mathrm{C} /$ $\mathrm{N}$ indica a humificação da matéria orgânica do solo, que passa a sofrer uma lenta mineralização de seus nutrientes.

A grande riqueza florística da área, o alto percentual de espécies com populações de baixa densidade e o fato do estudo ter sido realizado numa encosta irregular, abrangendo distintas situações topográficas e sucessionais, respondem pela insuficiência de amostragem constatada.

Para as espécies que se destacam em relação ao VI ou VC, constatam-se duas estratégias de ocupação do ambiente: muitos indivíduos de porte relativamente reduzido ou poucos indivíduos que podem alcançar grandes dimensões. Apresentam a primeira estratégia Neoraputia magnifica var. magnifica, Euterpe edulis, Chrysophyllum flexuosum, Calycorectes sellowianus, Lonchocarpus filipes, Guarea kunthiana, Pausandra megalophylla, Psychotria subspathacea e Quararibea turbinata, enquanto Gallesia integrifolia, Chrysophyllum lucentifolium subs. lucentifolium, Micropholis crassipedicellata e Pouteria filipes apresentam a segunda.

Para todos os parâmetros fitossociológicos analisados, a grande maioria das espécies apresenta valores baixos e semelhantes, traduzindo a pequena contribuição de cada uma para a estrutura da mata. Este é um padrão característico de florestas tropicais, que tem sido encontrado em florestas brasileiras.

Apesar de Myrtaceae apresentar grande destaque em relação ao número de indivíduos amostrados, considera-se que não haja uma nítida dominância desta família na mata estudada.

As famílias que se destacam quanto ao número de espécies são: Myrtaceae, Sapotaceae, Lauraceae e, em menor escala, Rubiaceae, Meliaceae, Moraceae e Leguminosae.

As famílias Sapotaceae, Myrtaceae, Rutaceae, Meliaceae, Palmae, Moraceae, Euphorbiaceae, Leguminosae, Rubiaceae, Phytolaccaceae, Bombacaceae e Lauraceae destacam-se quanto ao valor de importância. Para algumas destas famílias, nota-se que uma única espécie contribui decisivamente ou responde sozinha por tal. É o caso de Neoraputia magnifica var. magnifica (Rutaceae), Euterpe edulis (Palmae) e Gallesia integrifolia (Phytolaccaceae).

As contribuições diferenciadas da densidade, frequência e dominância relativas na composição do VI das famílias traduzem tendências no sentido de diferentes estratégias de ocupação do ambiente. Na área, Myrtaceae, Rutaceae, Meliaceae, Palmae, Euphorbiaceae, Leguminosae e Rubiaceae prevalecem pelo número de indivíduos, enquanto Sapotaceae, Moraceae, Phytolaccaceae e, em menor escala, Bombacaceae, pela biomassa. Para Lauraceae, estes parâmetros contribuem mais uniformemente.

O índice de diversidade de Shannon encontrado $\left(H^{\prime}=4,20\right)$, um dos mais altos já registrados para a Mata Atlântica, é reflexo da grande riqueza em espécies (138) e da alta equabilidade $(\mathrm{J}=0,85)$.

A mata apresenta dois estratos arbóreos quase contínuos $(1,8-18 \mathrm{~m} ; 20-30 \mathrm{~m})$ e emergentes (até $45 \mathrm{~m}$ ), sendo que, das 10 espécies mais importantes, 8 são exclusivas do estrato inferior. Em relação as famílias mais importantes, Myrtaceae, Rutaceae, Meliaceae, Palmae, Rubiaceae e Lauraceae ocorrem exclusivamente ou preferencialmente no estrato inferior, enquanto Moraceae, Phytolaccaceae e Bombacaceae são 
características do estrato superior. Já Sapotaceae, Euphorbiaceae e Leguminosae estão mais equitativamente distribuídas em ambos os estratos.

A curva diferencial, apesar de sugerir uma distribuição mais contínua das alturas das árvores amostradas, permite o reconhecimento dos estratos definidos a partir do histograma de frequência das classes de altura.

A distribuição de frequência das classes de diâmetro de todas as árvores vivas amostradas apresenta a forma de um ' $J$ ' invertido, embora não balanceada. A grande concentração de indivíduos na primeira classe está relacionada, em parte, ao método utilizado para o cálculo do intervalo de classe.

Considerando-se, principalmente, a regeneração abundante e a estrutura populacional estável das espécies mais numerosas, sugere-se que a mata estudada encontra-se, possivelmente, em clímax ou estágio sucessional muito próximo disto. Entretanto, a continuidade da caça de mamíferos e captura de pássaros, responsáveis pela dispersão de muitas espécies vegetais, pode gerar, a médio prazo, alterações na estrutura da vegetação.

É necessário, enfim, que haja uma mudança de mentalidade por parte das autoridades e população em geral, para assegurar a perpetuação da vasta diversidade biológica encontrada no Brasil. Neste sentido, uma medida de grande importância é, sem dúvida, a ampliação e efetivação do sistema de unidades de conservação.

\section{AGRADECIMENTOS}

Os autores desejam agradecer a todos que, de alguma forma, contribuíram para a realização deste trabalho, em especial:

À Coordenadoria de Aperfeiçoamento de Pessoal de Nível Superior, CAPES, e ao Conselho Nacional de Desenvolvimento Científico e Tecnológico, CNPq, pelas bolsas concedidas ao primeiro autor; à Fundação Estadual de Engenharia do Meio Ambiente, FEEMA, pela autorização para o desenvolvimento deste trabalho na Estação Ecológica Estadual do Paraíso; à Prof ${ }^{a}$. Dra. Graziela M. Barroso, pela determinação do material de Myrtaceae; aos Pesquisadores Mário Gomes, Cyl Farney C. de Sá, Angela M.S. da F. Vaz, Marli P.M. de Lima, Haroldo C. de Lima, Willian A. Rodrigues, Cristiane M.B. Correia, Nilda Marquete F. da Silva, Ísis de A. Araújo, Cláudia M. Vieira, André Márcio A. Amorim, Marcus Nadruz, Lúcia d'A. Freire de Carvalho, Elsie F. Guimarães, Ariane L. Peixoto, Ronaldo Marquete, Alexandre Quinet, João Marcelo A. Braga e Sebastião J. da Silva Neto e bolsistas Carlos Eduardo de S. Santos e Ana Joffily, pela colaboração na determinação do material botânico. Ao auxiliar técnico Jorge C. Gomes pela inestimável ajuda nas atividades de campo.

\section{REFERÊNCIAS BIBLIOGRÁFICAS}

Baruqui, A. M. 1983. Comentários sobre a descrição e resultados analíticos de um perfil de solo. Informe Agropecuário, Belo Horizonte, 9(105): 33-44.

Bernardes, L. M. C. 1952. Tipos de clima do Estado do Rio de Janeiro. Revista Brasileira de Geografia 14(1): 57-80.

Bertoni, J. E. De A.; Martins, F. R.; Moraes, J. L. De \& Shepherd, G. J. 1988. Composição florística e estrutura fitossociológica do Parque Estadual de Vaçununga, Santa Rita do Passa Quatro, SP - gleba Praxedes. Bol. Técn. IF. São Paulo, 42: 149-170.

Blair, T. A. \& Fite, R. C. 1964. Meteorologia; tradução de Farid Cezar Chede. Rio de Janeiro, Missão Norte-Americana de Cooperação Econômica e Técnica no Brasil, Ao Livro Técnico S.A., 406 p.

Cavassan, O.; Cesar, O. \& Martins, F. R. 1984. Fitossociologia da vegetação arbórea da Reserva Estadual de Bauru, Estado de São Paulo. Revta brasil. Bot. 7(2): 91106.

Cesar, O. 1988. Composição florística, fitossociologia e ciclagem de nutrientes em mata mesófila 
Composição florística e estrutura do componente arbóreo de um trecho de Mata Atlântica na

Estação Ecológica Estadual do Paraíso, Cachoeiras de Macacu, Rio de Janeiro, Brasil

semidecídua (Fazenda Barreiro Rico, Mun. Anhembi (SP)). Rio Claro, Tese de Livre-Docência, Instituto de Biociências, UNESP.

Cochrane, T. T.; Sánchez, L. G.; Porras, J. A.; Azevedo, L. G. De \& Garver, C. L. 1985. Land in tropical America. Cali, CIAT, EMBRAPA-CPAC, v. 1, 146 p.

Comissão de Estudos para o Tombamento do

Sistema Serra do Mar/Mata Atlântica no Estado do Rio de Janeiro. 1991.

Tombamento da Serra do Mar/Mata Atlântica. Relatório final. Rio de Janeiro, $37 \mathrm{p}$.

Cottam, G. \& Curtis, J. T. 1956. The use of distance measures in phytosociological sampling. Ecology 37(3): 451-460.

Cronquist, A. 1988. The evolution and classification of flowering plants. $2^{\mathrm{a}}$ ed. New York, The New York Botanical Garden, 555 p.

Daubenmire, R. 1968. Plant communities: a textbook of plant synecology. New York, Evanston, London, Harper \& Row, Publishers, $300 \mathrm{p}$.

Davis, D. E. 1945. The annual cycle of plants, mosquitoes, birds, and mammals in two brazilian forests. Ecological Monographs 15(3): 243-295.

Delamônica, P.; Oliveira, R. R. De; Lima, D. F. de \& Toffoli, D. Di G. Dinâmica sucessional em um trecho de Floresta Atlântica sujeita ao manejo caiçara na Ilha Grande, RJ. I: áreas de 3 e 10 anos. Submetido à Revta brasil. Bot.

Duchaufour, P. 1982. Pedology. Great Britain, George Allen \& Unwin, $448 \mathrm{p}$.

EMBRAPA. 1979. Manual de métodos de análise de solo. Rio de Janeiro, EMBRAPA-SNLCS, $255 \mathrm{p}$. 1988. Critérios para distinção de classes de solos e de fases de unidades de mapeamento: normas em uso pelo SNLCS. Rio de

Janeiro, EMBRAPA-SNLCS

(Documentos, 11), $67 \mathrm{p}$.

$$
\text { Levantamento de }
$$

reconhecimento de baixa intensidade dos solos do Estado do Rio de Janeiro; escala 1:250.000. EMBRAPA-CNPS (inéd.).

Felfili, J. M. \& Silva-júnior, M. C. da. 1988. Distribuição dos diâmetros numa faixa de cerrado na Fazenda Água Limpa (FAL) em Brasília-DF. Acta bot. bras. 2(1-2): 85-105.

Gentry, A. H.; Herrera-macbryde, O.; Huber, O.; Nelson, B. W. \& Villamil, C. B. 1997. Regional overview: South America. In: WWF \& IUCN. Centres of plant diversity. A guide and strategy for their conservation. Cambridge, IUCN Publications Unit, v. 3, p. 269-307.

Giulietti, A. M. \& Forero, E. 1990. "Workshop" Diversidade taxonômica e padrões de distribuição das Angiospermas brasileiras - Introdução. Acta bot. bras. 4(1): 3-10.

Guedes, R. R. 1988. Composição florística e estrutura de um trecho de mata perturbada de baixada no Município de Magé, Rio de Janeiro. Arq. Jard. Bot. Rio de Janeiro 29: 155-200.

Guedes-Bruni, R. R. \& Lima, H. C. de. 1997. Mountain ranges of Rio de Janeiro South-eastern Brazil. In: WWF \& IUCN. Centres of plant diversity. A guide and strategy for their conservation. Cambridge, IUCN Publications Unit, v. 3, p. 376-380. ; Pessoa, S. De V. A. \& Kurtz, B.c. 1997. Florística e estrutura do componente arbustivo-arbóreo de um trecho preservado de floresta montana na Reserva Ecológica de Macaé de Cima. In: Lima, H.C. de \& GuedesBruni, R.R. (eds.) Serra de Macaé de Cima: Diversidade florística e conservação em Mata Atlântica. Rio de Janeiro, Instituto de Pesquisas Jardim Botânico do Rio de Janeiro, p. 127-145. Hartshorn, G. S. 1980. Neotropical forest dynamics. Biotropica 12(2) (suppl.): 
23-30.

Heinsdijk, D. 1965. A distribuição dos diâmetros nas florestas brasileiras. Boletim do Setor de Inventários Florestais do Ministério da Agricultura 11: 1-56.

Hilty, S. L. 1980. Flowering and fruiting periodicity in a premontane rain forest in Pacific Colombia. Biotropica 12(4): 292-306.

IUCN. 1988. Brazil: Atlantic Coastal

Forests. Cambridge, Tropical Forest Programme, Conservation Monitoring Centre, $19 \mathrm{p}$.

Janzen, D. H. 1980. Ecologia vegetal nos trópicos; tradução de James Robert Coleman, revisão técnica de Antônio Lamberti. São Paulo, Ed. Pedagógica e Universitária, Ed. da Universidade de São Paulo (Temas de Biologia, v. 7 ), 79 p.

Joly, C. A.; Leitão-filho, H. F. \& Silva, S. M. 1991. O patrimônio florístico. In: Cecchi, J.C. \& Soares, M.S.M. (coords.) Mata Atlântica/Atlantic Rain Forest. Ed. Index, Fundação SOS Mata Atlântica, p. 95-125.

Klein, R. M. 1990. Estrutura, composição florística, dinamismo e manejo da "Mata Atlântica" (floresta ombrófila densa) do sul do Brasil. In: II Simpósio de Ecossistemas da Costa Sul e Sudeste Brasileira: estrutura, função e manejo, Águas de Lindóia, SP. Anais, v. 1, p. 259-286.

Koeppen, W. 1948. Climatologia; versão para o espanhol de Pedro R. Hendrichs Pérez. México, Fondo de Cultura Econômica, 466 p.

Leitão-filho, H. de F. 1987. Considerações sobre a florística de florestas tropicais e sub-tropicais do Brasil. IPEF, Piracicaba, 35: 41-46. 1993. (coord.) Ecologia da Mata Atlântica em Cubatão (SP). São Paulo, Campinas, Ed. da Universidade Estadual Paulista, Ed. da Universidade de Campinas, $184 \mathrm{p}$.
Lepsch, I. F. 1993. Solos: formação e conservação. 5a ed. São Paulo, Melhoramentos (Série Prisma), 157 p.

Magurran, A. E. 1988. Ecological diversity and its measurement. London, Croom Helm Limited, 179 p.

Mantovani, W. 1993. Estrutura e dinâmica da Floresta Atlântica na Juréia, Iguape - SP. São Paulo, Tese de LivreDocência, Instituto de Biociências, USP, $126 \mathrm{p}$.

; Rodrigues, R. R.; Rossi, L.; Romaniuc-neto, S.; Catharino, E. L. M. \& Cordeiro, I. 1990. A vegetação na serra do Mar em Salesópolis, SP. In: II Simpósio de Ecossistemas da Costa Sul e Sudeste Brasileira: estrutura, função e manejo, Águas de Lindóia, SP. Anais, v. 1, p. 348-384.

Martins, F. R. 1989. Fitossociologia de florestas do Brasil: um histórico bibliográfico. Pesquisas (Botânica) 40: 103-164. . 1993. Estrutura de uma floresta mesófila. $2^{a}$ ed. Campinas, Ed. da UNICAMP (Série Teses), 246 p.

Martins, H. F.; Coimbra-Filho, A. F.; Kaulfmann, E.; Carvalho, J. A. De O.; Magnanini, A. \& Moreira, E. A. B. 1989. Plano Diretor - Estação Ecológica Estadual do Paraíso. Fundação Estadual de Engenharia do Meio Ambiente, 28 p. e anexos (datilogr.).

Matthes, L. A. F. 1980. Composição florística, estrutura e fenologia de uma floresta residual do planalto paulista: Bosque dos Jequitibás (Campinas, SP). Campinas, Dissertação de Mestrado, Instituto de Biologia, UNICAMP, 209 p.

Mayo, S. J. \& Fevereiro, V. P. B. 1982. Mata de Pau Ferro: a pilot study of the brejo forest of Paraíba, Brazil. Great Britain, Royal Botanic Gardens, Kew, Winston Churchill Memorial Trust, 29 p. Melo, M. M. R. F. de \& Mantovani, W. 1994. Composição florística e estrutura de 
trecho de Mata Atlântica de encosta, na Ilha do Cardoso (Cananéia, SP, Brasil). Boletim do Instituto de Botânica 9: 107-158.

Morellato, L. P. C. \& Leitão-filho, H. F. 1992. Padrões de frutificação e dispersão na serra do Japi. In: Morellato, L .P. C. (org.) História natural da serra do Japi: ecologia e preservação de uma área florestal no sudeste do Brasil. Campinas, Ed. da UNICAMP, FAPESP, p. 112-140.

Moreno, M. R.; Nascimento, M. T. \& Kurtz, B. C. 1998. Estrutura e composição florística do estrato arbóreo em duas zonas altitudinais diferentes em Mata Atlântica de encosta na região do Imbé - RJ: primeira aproximação. In: IV Simpósio de Ecossistemas Brasileiros, Águas de Lindóia, SP. Anais, v. 2, p. 64-70.

Mori, S. A. 1989. Eastern, extra-Amazonian Brazil. In: Campbell, D.G. \& Hammond, H.D. (eds.) Floristic inventory of tropical countries: the status of plant systematics, collections, and vegetation, plus recommendations for the future. New York, The New York Botanical Garden, p. 427-454.

; Boom, B. M. \& Prance, G. T.

1981. Distribution patterns and conservation of eastern brazilian coastal forest tree species. Brittonia 33(2): 233-245.

; Boom, B. M.; Carvalho, A. M. de \& Santos, T. S. dos. 1983. Southern bahian moist forests. The Botanical Review 49(2): 155-232.

Myers, N. 1988. Tropical forests and their species: going, going ...? In: Wilson, E.O. (ed.) Biodiversity. Washington, D.C., National Academy Press, p. 28-35.

Oliveira, J. B. de; Jacomine, P. K. T. \& Camargo, M. N. 1992. Classes gerais de solos do Brasil: guia auxiliar para seu reconhecimento. Jaboticabal, FUNEP, $201 \mathrm{p}$.
Oliveira, R. R.; Zaú, A. S.; Lima, D. F.; Silva, M. B. R.; Vianna, M. C.; Sodré, D. O. \& Sampaio, P. D. 1995. Significado ecológico da orientação de encostas no maciço da Tijuca, Rio de Janeiro. In: Esteves, F.A. (ed.) Oecologia brasiliensis: estrutura, funcionamento e manejo de ecossistemas brasileiros. Rio de Janeiro, Ed. da UFRJ, v. 1, p. 523-541.

Pagano, S. N.; Leitão-filho, H. De F. \& Shepherd, G. J. 1987. Estudo fitossociológico em mata mesófila semidecídua no Município de Rio Claro (Estado de São Paulo). Revta brasil. Bot. 10: 49-61.

Peixoto, A. L. 1991/92. Vegetação da costa atlântica. In: Monteiro, S. \& Kaz, L. (coords.) Floresta Atlântica. Rio de Janeiro, Edições Alumbramento, Livroarte Editora, p. 33-42. \& Gentry, A. 1990. Diversidade e composição florística da mata de tabuleiro na Reserva Florestal de Linhares (Espírito Santo, Brasil). Revta brasil. Bot. 13: 19-25.

Pessoa, S. de V. A.; Guedes-Bruni, R. R. \& Kurtz, B. C. 1997. Composição florística e estrutura do componente arbustivoarbóreo de um trecho secundário de floresta montana na Reserva Ecológica de Macaé de Cima. In: Lima, H.C. de $\&$ Guedes-Bruni, R.R. (eds.) Serra de Macaé de Cima: Diversidade florística e conservação em Mata Atlântica. Rio de Janeiro, Instituto de Pesquisas Jardim Botânico do Rio de Janeiro, p. 147-167.

Polhill, R. M.; Raven, P. H. \& Stirton, C. H. 1981. Evolution and systematics of the Leguminosae. In: Polhill, R.M. \& Raven, P.H. (eds.) Advances in legume systematics. Kew, Richmond, Surrey, Royal Botanic Gardens, parte 1, p. 1-26.

PROGRAMA MATA ATLÂNTICA. 1992. Relatório Técnico. Jardim Botânico 
do Rio de Janeiro/IBAMA, Linhas de Ação em Botânica/CNPq, John D. \& Catherine T. MacArthur Foundation, Shell do Brasil S.A., Instituto PróNatura, 75 p.

Raij, B. van. 1991. Fertilidade do solo e adubação. Piracicaba, CERES, Potafos, P. 137-162.

Richards, P. W. 1981. The tropical rain forest: an ecological study. $2^{a}$ ed. Cambridge, New York, Melbourne, Cambridge University Press, $450 \mathrm{p}$.

Rodrigues, H. C. 1996. Composição florística e fitossociológica de um trecho de Mata Atlântica na Reserva Biológica do Tinguá, Nova Iguaçu, Rio de Janeiro. Rio de Janeiro, Dissertação de Mestrado, Museu Nacional, UFRJ, 77 p.

Rodrigues, R. R. 1986. Levantamento florístico e fitossociológico das matas da serra do Japi, Jundiaí, SP. Campinas, Dissertação de Mestrado, Instituto de Biologia, UNICAMP, 198 p.

Rosot, N. C.; Machado, S. do A. \& FigueiredoFilho, A. 1982. Análise estrutural de uma floresta tropical como subsídio básico para elaboração de um plano de manejo florestal. Silvic. SP. 16A(1) (Anais do Congresso Nacional sobre Essências Nativas): 468-490.

Sampaio, P. D. 1997. Florística e estrutura de Floresta Atlântica secundária Reserva Biológica Estadual da Praia do Sul, Ilha Grande, RJ. São Paulo, Dissertação de Mestrado, Instituto de Biociências, USP, 113 p.

Silva, A. F. da. 1980. Composição florística e estrutura de um trecho da Mata Atlântica de encosta no Município de Ubatuba - São Paulo. Campinas, Dissertação de Mestrado, Instituto de Biologia, UNICAMP, 153 p. 1989. Composição florística e estrutura fitossociológica do estrato arbóreo da Reserva
Florestal Professor Augusto Ruschi, São José dos Campos - SP. Campinas, Tese de Doutorado, Instituto de Biologia, UNICAMP, 162 p.

\& Leitão-Filho, H. de F. 1982.

Composição florística e estrutura de um trecho da Mata Atlântica de encosta no Município de Ubatuba (São Paulo, Brasil). Revta brasil. Bot. 5: 43-52.

Soulé, M. E. 1990. The real work of systematics. Ann. Missouri Bot. Gard. 77(1): 4-12.

Struffaldi-De Vuono, Y. 1985. Fitossociologia do estrato arbóreo da floresta da Reserva Biológica do Instituto de Botânica (São Paulo, SP). São Paulo, Tese de Doutorado, Instituto de Biociências, USP.

Sugiyama, M. 1993. Estudo de florestas na restinga da Ilha do Cardoso, Cananéia, SP. São Paulo, Dissertação de Mestrado, Instituto de Biociências, USP, $115 \mathrm{p}$.

Tarifa, J. R. 1970. Estudo preliminar das possibilidades agrícolas da região de Presidente Prudente, segundo o balanço hídrico de Thornthwaite (1948-1955). Boletim Geográfico 29(217): 34-54.

Thornthwaite, C. W. 1948. An approach toward a rational classification of climate. Geographical Review 38: 5594.

Veloso, H. P. 1945. As comunidades e as estações botânicas de Teresópolis, Estado do Rio de Janeiro (com um ensaio de uma chave dendrológica). Bol. Mus. Nac. Rio de Janeiro, Bot. 3: $1-95$.

\& Klein, R. M. 1957. As comunidades e associações vegetais da mata pluvial do sul do Brasil: I. As comunidades do Município de Brusque, Estado de Santa Catarina. Sellowia 9: 81-235.

; Rangel-Filho, A. L. R. \& Lima, J. C. A. 1991. Classificação da vegetação brasileira, adaptada a um 
Composição florística e estrutura do componente arbóreo de um trecho de Mata Atlântica na

Estação Ecológica Estadual do Paraíso, Cachoeiras de Macacu, Rio de Janeiro, Brasil

sistema universal. Rio de Janeiro, IBGE, Departamento de Recursos Naturais e Estudos Ambientais, 124 p.

Walter, H. 1971. Ecology of tropical and subtropical vegetation; versão para o inglês de Dieter Mueller-Dombois. Edinburgh, Oliver \& Boyd, 539 p.

Wilson, E. O. 1988. The current state of biological diversity. In: Wilson, E.O. (ed.) Biodiversity. Washington, D.C., National Academy Press, p. 3-18.

Zar, J. H. 1996. Biostatistical analysis. $3^{\mathrm{a}}$ ed. Upper Saddle River, Prentice-Hall, Inc., $662 \mathrm{p}$. 
